\title{
Targeted inhibition of Wnt signaling with a bacterial toxin fragment suppresses breast cancer tumor- initiating/chemo-resistant cells
}

\section{Aina He}

Boston Children's Hospital

\section{Dongxi Xiang}

Division of Genetics, Department of Medicine, Brigham and Women's Hos

\section{Oded Kopper}

Hubrecht Institute

\section{Daniel Horan}

Department of Anatomy \& Cell Biology, Indiana University School of Medicine

\section{Peng Chen}

Department of Physiology and Biophysics, University of California, Irvine

\section{Roderick Bronson}

Dana Farber Cancer Center, Harvard Cancer Center

\section{Ren Sheng}

Kirby Neurobiology Center, Boston Children's Hospital, Department of Neurology, Harvard Medical

School

\section{Hao Wu}

Boston Children's Hospital

\section{Lufei Sui}

Boston Children's Hospital

\section{Kun Zhou}

Department of Vascular Biology, Boston Children's Hospital

\section{Liang Tao}

Westlake University https://orcid.org/0000-0003-3441-698X

\section{Songhai Tian}

Department of Urology, Boston Children's Hospital, and Department of Surgery, Harvard Medical School, Boston, MA 02115, USA

\section{Quan Wu}

Boston Children's Hospital

\section{Yujing Huang}

Shanghai Jiaotong University Affiliated Sixth People's Hospital

\section{Zan Shen}


Shanghai Jiaotong University Affiliated Sixth People's Hospital

\section{Hong Chen}

Boston Children's Hospital

\section{Xi He}

Boston Children's Hospital

\section{Alexander Robling}

Indiana University School of Medicine

\section{Rongsheng Jin}

Department of Physiology and Biophysics, University of California, Irvine

\section{Hans Clevers}

Hubrecht Institute for Developmental Biology and Stem Cell Research https://orcid.org/0000-00023077-5582

\section{Zhe Li}

Brigham and Women's Hospital

\section{Min Dong ( $D$ Min.Dong@childrens.harvard.edu )}

Boston Children's Hospital https://orcid.org/0000-0002-1744-7293

\section{Article}

Keywords: breast cancer, BRCA1, Wnt signaling, mammary tumor cells

Posted Date: August 31st, 2020

DOI: https://doi.org/10.21203/rs.3.rs-58989/v1

License: (c) (1) This work is licensed under a Creative Commons Attribution 4.0 International License.

Read Full License 
1 Targeted inhibition of Wnt signaling with a bacterial toxin fragment

2 suppresses breast cancer tumor-initiating/chemo-resistant cells

3 Aina $\mathrm{He}^{1,2,3 *}$, Dongxi Xiang ${ }^{4,5 *}$, Oded Kopper ${ }^{6}$, Daniel J. Horan ${ }^{7}$, Peng Chen ${ }^{8}$, Roderick T.

4 Bronson ${ }^{9}$, Ren Sheng ${ }^{10}$, Hao Wu ${ }^{11}$, Lufei Sui ${ }^{11}$, Kun Zhou ${ }^{11}$, Liang Tao ${ }^{2,3}$, Songhai Tian ${ }^{2,3}$, Quan

$5 \mathrm{Wu}^{2,3,12}$, Yujing Huang ${ }^{1}$, Zan Shen ${ }^{1}$, Hong $\mathrm{Chen}^{11}$, Xi He${ }^{10}$, Alexander G Robling ${ }^{7}$, Rongsheng

6 Jin $^{8}$, Hans Clevers ${ }^{6}$, Zhe Li ${ }^{4,5 \#}$, and Min Dong ${ }^{2,3 \#}$

$7 \quad{ }^{1}$ Department of Oncology, Shanghai Jiaotong University Affiliated Sixth People's Hospital, No.

8 600, Yishan Road, 200233 Shanghai, PR China.

$9{ }^{2}$ Department of Urology, Boston Children's Hospital, Harvard Medical School, Boston, 10 Massachusetts 02115, USA.

$11{ }^{3}$ Department of Microbiology and Immunobiology and Department of Surgery, Harvard Medical

12 School, Boston, Massachusetts 02115, USA

$13{ }^{4}$ Division of Genetics, Department of Medicine, Brigham and Women's Hospital, Boston, 14 Massachusetts 02115, USA.

$15{ }^{5}$ Department of Medicine, Harvard Medical School, Boston, Massachusetts 02115, USA.

$16{ }^{6}$ Hubrecht Institute, Royal Netherlands Academy of Arts and Sciences and University Medical

17 Center Utrecht, Uppsalalaan 8, 3584 CT Utrecht, the Netherlands.

$18{ }^{7}$ Department of Anatomy \& Cell Biology, Indiana University School of Medicine, 635 Barnhill 19 Dr., MS 5025J, Indianapolis, IN 46202, USA.

$20{ }^{8}$ Department of Physiology and Biophysics, University of California, Irvine, Irvine, CA, USA.

$21{ }^{9}$ Rodent Histopathology, Harvard Medical School, Boston, Massachusetts 02115, USA.

$22{ }^{10}$ Kirby Neurobiology Center, Boston Children's Hospital, Department of Neurology, Harvard 23 Medical School, Boston, Massachusetts 02115, USA.

$24{ }^{11}$ Department of Vascular Biology, Boston Children's Hospital, Boston, Massachusetts 02115, 25 USA.

$26{ }^{12}$ Central Laboratory of Medical Research Centre, The First Affiliated Hospital of USTC, 27 Division of Life Sciences and Medicine, University of Science and Technology of China, Hefei, 28 Anhui 230001, China.

*These authors contributed equally to this work.

$31 \quad{ }^{\#}$ Corresponding authors: Emails: zli4@ @rics.bwh.harvard.edu; min.dong@ childrens.harvard.edu 


\section{ABSTRACT}

34 BRCA1 germ-line mutations are a major cause of hereditary breast cancer and BRCA1-deficient

35 breast cancer shares many characteristics as sporadic basal-like breast cancer (BLBC). Effective 36 therapeutic targets for BRCA1-deficient BLBC remain lacking. By utilizing a BRCA1-deficient 37 BLBC mouse model based on intraductal injection of $\mathrm{Krt} 8$-Cre adenovirus to inactivate Brcal 38 and Trp53 in luminal mammary epithelial cells, here we report that the Wnt receptor Frizzled 7 39 (FZD7) serves as a biomarker and therapeutic target in the resulting mammary tumor cells and is 40 particularly enriched in cancer stem cells / tumor-initiating cells (CSCs/TICs). Inhibiting FZD7-

41 mediated Wnt signaling using a nontoxic FZD-binding fragment of $C$. difficile toxin $\mathrm{B}\left(\mathrm{TcdB}{ }^{\mathrm{FBD}}\right)$ 42 attenuates growth of BRCA1-deficient tumor organoids and xenografted tumors, without 43 damaging Wnt-sensitive tissues such as bones in vivo. Finally, FZD1/2/7-positive cells are 44 enriched in chemotherapy-resistant cells in both BLBC and luminal breast tumors treated with 45 cisplatin, and $\mathrm{TcdB}^{\mathrm{FBD}}$ synergizes strongly with cisplatin in inhibiting both tumor types. These 46 findings demonstrate the therapeutic value for targeting FZD1/2/7 in treating breast cancers and 47 establish $\mathrm{TcdB}^{\mathrm{FBD}}$ as a potential therapeutic agent targeting $\mathrm{TICs}$ and chemotherapy-resistant 48 cancer cells. 
INTRODUCTION

Breast cancers are heterogeneous and different subtypes require distinct treatments $(1,2)$.

52 Targeted therapy in breast cancer is most successful when subtype-specific key pathways that

53 drive cancer cell growth are defined and serve as therapeutic targets. Among breast cancer

54 subtypes, estrogen receptor $(\mathrm{ER})^{+}$luminal breast cancers are treated by endocrine therapy (e.g.,

55 aromatase inhibitor, tamoxifen) that targets the ER signaling pathway, whereas breast cancers

56 with HER2 overexpression can be targeted by Trastuzumab (Herceptin), a monoclonal antibody

57 that blocks HER2 signaling. Basal-like breast cancer (BLBC) largely overlaps with triple-

58 negative breast cancer (TNBC), which lacks ER and progesterone receptor (PR) expression and

59 HER2 overexpression (3). BLBC/TNBCs lack clear driver mutations, as evident from recent

60 sequencing studies (4). Thus, treatment of BLBC/TNBCs relies on standard chemotherapy, with

61 the worst prognosis among all breast cancer subtypes (5). In addition, even among luminal breast

62 cancers, those belonging to the luminal B subtype have high proliferation index and often do not

63 respond to endocrine therapy well; thus, they are treated by chemotherapy as well (6).

64 Chemotherapy can eliminate the bulk of cancer cells, but inevitably therapy-resistant cancer cells

65 emerge, which typically possess stem cell-like properties $(7,8)$. In order to eliminate these cells,

66 it is important to define key programs that sustain their stemness so that therapeutic approaches

67 can be designed to target them.

Wnt/ $\beta$-catenin signaling plays key roles in stem cell self-renewal and injury repair (9). Mutations in components of the Wnt pathways are well-established as a dominant causal factor

70 in colorectal cancer and subgroups of many other solid tumors $(9,10)$. The therapeutic value of

71 targeting Wnt signaling in these tumors are well established using numerous animal models and

72 by a number of broad-spectrum pan-Wnt signaling inhibitors $(9,10,14)$. Upregulation of Wnt

73 signaling without any mutations in the pathways has also been broadly implicated in cancer

74 development, epithelial-mesenchymal transition (EMT), metastasis, chemotherapy-resistance,

75 and immune escape of a broad range of human cancers $(10,11,12)$, possibly reflecting a universal

76 requirement of Wnt signaling in maintaining the stemness of cancer cells. For instance, Wnt

77 pathway activation has been previously reported to be enriched in BLBC and predicts poor

78 outcome (13), and activation of Wnt signaling (without mutations in Wnt pathways) is observed

79 in $>50 \%$ of human breast cancer cases and is linked to reduced overall survival (10). These broad

80 range of tumors potentially can benefit from Wnt signaling inhibition, but the therapeutic 
81 efficacy of this approach remains to be established and the side effect associated with pan-Wnt 82 inhibition also diminishes the therapeutic value particularly on cancers without Wnt signaling 83 pathway mutations such as breast cancers $(15,16)$.

84 Wnt and its receptors, the 7-pass transmembrane protein Frizzled (FZDs), are a large 85 family $(9,17)$. One way to minimize side effects is to target the specific Wnt-FZD pair(s) 86 enriched in cancer cells. However, such a narrow spectrum inhibition has yet to be achieved in 87 vivo due to high degrees of homology among Wnt-FZD members. Concerns on potential 88 redundant expression of multiple Wnt-FZD pairs also raise the doubt on whether inhibiting a specific subgroup is sufficient to achieve any therapeutic effects in vivo.

There are ten FZD members in humans, divided into four subgroups (FZD1/2/7, 5/8, 3/6, 4/9/10) (17). They contain only one relatively small extracellular domain on their N-termini, designated cysteine-rich domain (CRD, 120-150 residues), which serves as the binding site for Wnt (17). As CRDs are highly conserved across all mammals and different FZD members, they are not good immunogens to generate high-affinity antibodies, let alone neutralizing antibodies capable of blocking Wnt binding and distinguishing FZD members. The most advanced Wntsignaling inhibition antibody, OMP-18R5 (developed by OncoMed Inc.), which was identified

97 through in vitro phage-display approach, has been under clinical trial (14). Even though OMP18R5 was originally developed to target only FZD7, it was found to bind five FZDs across two sub-groups (FZD1/2/7 and FZD5/8). Although OMP-18R5 showed anti-tumor efficacy in animal models, it exhibits adverse effects particularly loss of bone density in humans $(10,18)$. The similar side effect was also observed with a Fc fusion protein containing FZD8-CRD $(15,19)$, suggesting that bone density loss is a primary effect when both FZD1/2/7- and 5/8-mediated signaling pathways are blocked.

Here we have developed and evaluated a specific inhibitor targeting Wnt-FZD1/2/7 signaling utilizing a fragment of $C$. difficile toxin B, which uses FZD1/2/7 as its receptors $(20,21)$. Taking advantage of this specific inhibitor and utilizing several breast cancer mouse 107 models, we demonstrate that FZD1/2/7-mediated Wnt signaling plays a key role in mouse 108 models of BLBC and human BLBC organoids, as well as in chemotherapy-resistant mammary 109 tumor cells in both BLBC and luminal breast cancers. Inhibiting FZD1/2/7-mediated Wnt 110 signaling suppresses tumor growth and cancer stem cell activities and synergizes with 111 chemotherapy agent cisplatin, without side effects on bone density. These findings demonstrate 
112 both the feasibility and therapeutic value for targeting a single subgroup of FZDs in treating a 113 broad range of breast cancers.

114 


\section{RESULTS}

\section{FZD7 is the major FZD receptor expressed in BLBC}

To identify the specific subgroups of FZDs expressed in BLBC, we examined expression of all 10 FZD members in human breast cancers and murine models. In publicly available human breast cancer expression data, FZD5, 6, 7 and 9 are expressed at higher levels in BLBC cases than other subtypes (Supplementary Fig. S1). In a microarray dataset for various breast cancer

122 mouse models (22), $F z d 7$ and $F z d 6$ were highly expressed in C3(1)-Tag and Trp53-null ERnegative mammary tumors (Supplementary Fig. S2), both of which represent mouse models for human BLBC/TNBC (23).

To further examine Wnt signaling in murine breast cancer models, we focused on two commonly used models, the BLBC model C3(1)-Tag, the luminal B breast cancer model MMTVPyMT (23), as well as a novel BLBC mouse model we established recently with loss of p53 and BRCA1 (24). Our model is based on intraductal injection of a Cre-expressing adenovirus under the control of the keratin 8 (Krt8) promoter [Ad-K8-Cre (25)] to floxed Trp53 and Brcal female mice carrying the conditional Rosa26-LSL-EYFP (R26Y) reporter $\left(\operatorname{Trp} 53^{L / L} ; \mathrm{BrCal}^{L / L} ; R 26 Y\right)$ (Supplementary Fig. S3A-B). This approach somatically inactivates Brcal and Trp53 in luminal mammary epithelial cells (MECs), which are believed to serve as the cellular origin of BRCA1associated BLBC (26-28), leading to development of mammary tumors that closely resemble the human BLBC subtype (24). Overall, these three models represent mammary tumor types that are not good candidates for hormone or anti-HER2 therapies but can be treated by standard chemotherapy.

We first analyzed activation of Wnt signaling in these tumors by assessing their levels of active $\beta$-catenin (i.e., non-phosphorylated $\beta$-Catenin). Both p53/BRCA1-deficient tumors and C3(1)-Tag Basal-like (BL) tumors exhibited higher levels of active $\beta$-catenin than that of $M M T V-P y M T$ tumors, based on immunofluorescence (IF) staining and immunoblot analysis (Fig.

141 1A-C). Next, we measured expression levels of all $F z d$ genes in these mammary tumors by qRT142 PCR and found that only $F z d 7$ was expressed at higher levels in both p53/BRCA1-deficient and 143 C3(1)-Tag tumors, but not in MMTV-PyMT tumors, than all other Fzd genes (Fig. 1D).

144 We then analyzed normal mammary gland tissues by fluorescence-activated cell sorting 145 (FACS) with an APC-conjugated FZD7-specific antibody, which detected $~ 2.44 \%$ of cells as 
FZD7-positive (FZD7 ${ }^{+}$) (Fig. 1E). Further analysis using CD24 and CD29 as markers revealed

147 that $\mathrm{FZD}^{+}$cells are largely considered basal MECs ( 81.3\%, Fig. 1E). Compared to the normal mammary tissues, MMTV-PyMT tumor tissues contains similar levels of FZD7 ${ }^{+}$cells, whereas

149 both C3(1)-Tag and p53/BRCA1-deficient BL tumors, particularly the latter, contained elevated 150 levels of FZD7 ${ }^{+}$cells ( 6.05\% and $\sim 10.4 \%$, respectively, Fig. 1F and Supplementary Fig. S3C). 151 Together, these data suggest that $\mathrm{FZD7}^{+}$cells are enriched in BLBC tumor models.

\section{TcdB $^{\mathrm{FBD}}$ inhibits FZD1/2/7-mediated Wnt signaling in human breast cancer cell lines}

To evaluate whether FZD7 may serve as a therapeutic target for treating BLBC, we took advantage of our recent finding that a bacterial toxin $C$. difficile toxin B (TcdB) recognizes FZD1, 2, and 7 as its high-affinity receptors and toxin binding inhibits FZD1/2/7-mediated Wnt signaling (20). Our previous studies have also defined an FZD-binding domain in TcdB (amino acid residues 1285-1804, designated as $\mathrm{TcdB}^{\mathrm{FBD}}$, Fig. 2A) (21). Both $\mathrm{TcdB}^{\mathrm{FBD}}$ and Wnt recognize the CRDs. FZD1, 2, and 7 form a sub-group with nearly identical CRDs within the FZD family. The co-crystal structure of $\mathrm{TcdB}^{\mathrm{FBD}}$ in complex with CRD of FZD2 (CRD2) has been solved, revealing that $\mathrm{TcdB}^{\mathrm{FBD}}$ effectively blocks Wnt signaling by targeting a region in CRD that is critical for docking of the palmitate in Wnt (21). All Wnts are modified by lipidation through the addition of a palmitoleic acid (PAM) to a conserved serine, which is essential for their secretion and binding to FZDs. Binding of $\mathrm{TcdB}^{\mathrm{FBD}}$ prevents docking of the Wnt PAM into a hydrophobic groove in CRDs. Key residues for $\mathrm{TcdB}^{\mathrm{FBD}}$ interactions are conserved in CRD1, 2, and 7, but varies in other FZD members, which are the reasons for the selective high-affinity binding of $\mathrm{TcdB}^{\mathrm{FBD}}$ to $\mathrm{CRD} 1 / 2 / 7(21,29)$.

We first tested the ability of $\mathrm{TcdB}^{\mathrm{FBD}}$ to inhibit Wnt signaling in a human TNBC cell line MDA-MB-231 using a well-established TOPFLASH/TK-Renilla dual luciferase reporter assay.

171 analysis confirmed that FZD1/2/7 are expressed at higher levels than other subgroups of FZDs in 172 this cell line (Supplementary Fig. S4A). Wnt signaling in cells was stimulated using conditioned 173 medium containing WNT3A. Nanomolar levels of $\operatorname{TcdB}^{\mathrm{FBD}}$ inhibited WNT3A-mediated 174 signaling in a dose-dependent manner (Fig. 2B). This inhibitory effect sustained for over $72 \mathrm{~h}$ 175 with a single exposure to $\mathrm{TcdB}^{\mathrm{FBD}}$ in the medium (Fig. 2C). As a control, a mutant form of TcdB $176\left(\mathrm{TcdB}^{\mathrm{mu}}\right)$ that could no longer bind FZD1/2/7, constructed by replacing the key CRD-binding 
177 residues in $\mathrm{TcdB}^{\mathrm{FBD}}$ with the corresponding residues in $C$. difficile toxin A that does not use 178 FZDs as receptors $\left({ }^{1595}\right.$ VNFLQS changed to ${ }^{1596} \mathrm{GFE}$, Fig. 2A) (21) (31), showed no inhibition of 179 Wnt signaling at nanomolar concentrations (Fig. 2B-C). TcdB ${ }^{\mathrm{FBD}}$ did not affect viability of 180 MDA-MB-231 and a few other human cell lines (U2OS, 293T, and MCF7), confirming that this 181 toxin fragment does not have general toxicity to cells (Supplementary Fig. S4B).

To further evaluate the ability of $\mathrm{TcdB}^{\mathrm{FBD}}$ to inhibit Wnt signaling in vivo, we injected MDA-MB-231 cells with an integrated TOPFLASH reporter subcutaneously into 184 immunodeficient athymic nude mice, which resulted in tumor growth. Recombinantly purified $185 \mathrm{TcdB}^{\mathrm{FBD}}$ was subsequently injected intraperitoneally (i.p.) to these mice at a dose of $20 \mathrm{mg} / \mathrm{kg}$ 186 once per day for 6 times. To imaging the Wnt signaling activity, D-luciferin was injected $5 \mathrm{~min}$ 187 (i.p.) in vivo before tumors were dissected out, and their luminescence signals were then 188 measured ex vivo. Tumors from $\mathrm{TcdB}^{\mathrm{FBD}}$-treated mice showed $\sim 5$-fold reduced signals compared with tumors from vehicle-treated control groups and $\mathrm{TcdB}^{\mathrm{mu}}$-treated groups (Fig. 2D).

We next evaluated the specificity of $\mathrm{TcdB}^{\mathrm{FBD}}$ for targeting FZD1/2/7, but not other closely-related FZDs (e.g., FZD5). Two pancreatic cancer cell lines, PaTu8988s and HPAF-II, 192 are known to express high levels of FZD5 and are sensitive to small molecule pan-Wnt signaling 193 inhibitor, LGK974 (32), which targets the $O$-acyltransferase Porcupine required for 194 palmitoylation of all Wnts (33). While LGK974 treatment (at a concentration of $100 \mathrm{nM}$ ) 195 inhibited clonogenic growth as well as the sphere formation ability of these two cell lines, $196 \mathrm{TcdB}^{\mathrm{FBD}}$ treatment at a similar concentration $(150 \mathrm{nM})$ exhibited no growth inhibitory effect on 197 them in both assays (Supplementary Fig. S4C-E).

\section{TedB $^{\mathrm{FBD}}$ inhibits growth of BL mammary tumors}

To test whether $\mathrm{TcdB}^{\mathrm{FBD}}$ could affect BL mammary tumors with FZD7 expression, we first treated tumor organoids derived from the above-described murine models with $\mathrm{TcdB}^{\mathrm{FBD}}$ or $\mathrm{TcdB}^{\mathrm{mu}}$. Treatment with $\mathrm{TcdB}^{\mathrm{FBD}}$, but not $\mathrm{TcdB}^{\mathrm{mu}}$, reduced the size and number of organoids formed from the p53/BRCA1-deficient or C3(1)-Tag BL tumor cells; in contrast, $\mathrm{TcdB}^{\mathrm{FBD}}$ treatment did not affect growth of the organoids formed from $M M T V-P y M T$ luminal tumor organoids (Fig. 3A-C). Furthermore, TcdB ${ }^{\mathrm{FBD}}$-treated p53/BRCA1-deficient tumor organoids exhibited reduced expression of Wnt signaling-related genes (e.g., Axin2, Rnf43) and EMT- 
207 related genes (e.g., Vim, Zebl) compared with the control and $\mathrm{TcdB}^{\mathrm{mu}}$-treated organoids 208 (Supplementary Fig. S5A).

209 Next, we utilized $\mathrm{TcdB}^{\mathrm{FBD}}$ to evaluate whether inhibiting FZD7-mediated Wnt signaling 210 may offer any therapeutic benefits in vivo. Subcutaneous injection of p53/BRCA1-deficient 211 tumor organoid cells $\left(1 \times 10^{4}\right.$ cells $)$ into nude mice resulted in robust tumor growth. When 212 tumors reached $\sim 50 \mathrm{~mm}^{3}$, $\mathrm{TcdB}^{\mathrm{FBD}}$ was injected i.p. into the recipient mice. $\mathrm{TcdB}^{\mathrm{FBD}}$ 213 administration at a dose of 20 or $50 \mathrm{mg} / \mathrm{kg}$ with the intervals indicated in Fig. 3D, but not that of $214 \mathrm{TcdB}^{\mathrm{mu}}$, attenuated tumor growth, although the effect is modest (Fig. 3D). At molecular levels, 215 genes related to Wnt signaling and EMT were downregulated in tumors from $\mathrm{TcdB}^{\mathrm{FBD}}$-treated 216 mice, compared with those in vehicle or $\mathrm{TcdB}^{\mathrm{mu}}$-treated groups (Supplementary Fig. S5B).

217 Consistently, expression of lymphocyte enhancer-binding factor 1 (LEF1), a representative Wnt 218 signaling effector, is reduced at protein levels (Supplementary Fig. S5C).

219 To further evaluate whether $\mathrm{TcdB}^{\mathrm{FBD}}$ could attenuate growth of human BLBC/TNBC 220 cells, we took advantage of a recently established biobank of over 100 primary and metastatic 221 human breast cancer organoid lines (34). We chose two organoid lines from this biobank, 74T 222 and 86T, which represent a luminal and a BL breast cancer line with low and high level of a 223 BRCA1-deficiency signature (i.e., signature 3), respectively (34). The luminal organoid line 74T 224 was insensitive to $\mathrm{TcdB}^{\mathrm{FBD}}$ treatment (Supplementary Fig. 6A). In contrast, growth of the BL 225 line $86 \mathrm{~T}$ organoids was attenuated by $\operatorname{TcdB}^{\mathrm{FBD}}$ (Supplementary Fig. 6B). Similar to the 226 p53/BRCA1-deficient xenograft model, the inhibitory effect is rather modest. These results are 227 consistent with the idea that Wnt signaling is not a driving force but rather one of the 228 contributing factors in tumorigenesis of breast cancers. Nevertheless, these findings demonstrate 229 that selective inhibition of FZD7-mediated signaling is sufficient to exhibit an inhibitory effect 230 on growth of mouse and human BLBC cells.

\section{TcdB $^{\mathrm{FBD}}$ treatment does not affect the intestine and bones}

233 We next analyzed whether inhibiting FZD7-mediated signaling by $\mathrm{TcdB}^{\mathrm{FBD}}$ at 234 therapeutically effective doses is tolerated in Wnt sensitive tissues such as the intestine and 235 bones. $\mathrm{TcdB}^{\mathrm{FBD}}$ was injected into mice at 20,50 , or $100 \mathrm{mg} / \mathrm{kg}$ twice a week for five weeks. 236 These mice showed similar weight gains comparable with the control mice (Fig. 4A). To 237 examine the potential impact on the intestine, we injected (i.p.) EdU, which incorporates into 
238 replicating DNAs and marks proliferating cells, at the end of the fifth week. The intestine 239 epithelium constantly turns over and newly generated cells are produced from stem cells located 240 the bottom of the crypt region. Wnt signaling is a key pathway regulating intestinal stem cells 241 and a reduction in EdU incorporation would reflect an inhibition on stem cell activity $(35,36)$.

242 The intestinal tissues were dissected out and EdU incorporation was measured. A shown in Fig. $2434 \mathrm{~B}, \mathrm{TcdB}^{\mathrm{FBD}}$ treatment at 20 and $50 \mathrm{mg} / \mathrm{kg}$ levels did not reduce EdU levels in the intestinal 244 tissues. There appears to be a slight reduction at $100 \mathrm{mg} / \mathrm{kg}$, but it did not reach statistical 245 significance.

246 Clinical trials with OMP-18R5, which blocks FZD1/2/7 and 5/8, revealed that bone 247 density loss is the single most critical side effect in humans (15). Consistently, mice treated with 248 pan-Wnt signaling inhibitors (Porcupine inhibitors LGK974 and ETC-1922159) exhibited loss of 249 bone volume and density even at doses $<10 \mathrm{mg} / \mathrm{kg}$ (37). We thus focused our analysis on bone 250 mass and architecture utilizing micro-computed tomography $(\mu \mathrm{CT})$ technology in mice treated 251 with $\mathrm{TcdB}^{\mathrm{FBD}}$ at 20, 50, and $100 \mathrm{mg} / \mathrm{kg}$ doses for five weeks. No differences were observed in 252 cancellous or cortical microstructure in the femur (Fig. 4C). Bone volume fraction (BV/TV), 253 trabecular number (Tb.N) and trabecular thickness (Tb.Th) in the distal femur metaphysis were 254 not affected by $\mathrm{TcdB}^{\mathrm{FBD}}$, neither did cortical bone parameters, e.g., cortical thickness (Ct.Th) 255 (Fig. 4D).

TcdB $^{\mathrm{FBD}}$ inhibits $\mathrm{FZD7}^{+}$tumor-initiating cells in vitro and in vivo

FACS analysis demonstrate that $\sim 90 \%$ of $\mathrm{TcdB}^{\mathrm{FBD}}$-bound cells from primary p53/BRCA1-deficient tumors were $\mathrm{FZD7}^{+}$(Supplementary Fig. S7A), confirming that $\mathrm{TcdB}^{\mathrm{FBD}}$ targeted $\mathrm{FZD}^{+}$cells in tumor tissues. As Wnt signaling plays key roles in maintaining stem cell activities, we next examined whether $\mathrm{TcdB}^{\mathrm{FBD}}$ affected the activity of TICs in the p53/BRCA1deficient tumor, utilizing the mammosphere/tumorsphere assay that enriches TICs by culturing cancer cells in suspension $(38,39)$. A small percentage of these cells can survive and grow in

264 suspension as spheroids, which often correlates with their ability to form tumors in mice and thus they are considered as TICs. Dissociated tumor cells from the p53/BRCA1-deficient model easily formed spheroids (i.e., tumorspheres) in suspension culture (Supplementary Fig. S7B).

267 FACS analysis revealed that $\sim 85.7 \%$ of cells forming tumorspheres are $\mathrm{FZD}^{+}$, confirming that 268 most TICs express FZD7 (Supplementary Fig. S7C). TcdB ${ }^{\mathrm{FBD}}$ treatment greatly reduced sphere 
269 formation of p53/BRCA1-deficient mammary tumor cells (Fig. 5A). After TcdB ${ }^{\mathrm{FBD}}$ treatment, 270 the percentage of tumorsphere formation in the first passage was 1.2-fold reduced compared to 271 that of control, increased to 1.7-fold reduction at the second passage, and became even more 272 profound in the third passage (26.0-fold reduction) (Fig. 5B). This data indicate that TcdB ${ }^{\mathrm{FBD}}$ 273 inhibited the self-renewal potential of p53/BRCA1-deficient tumor cells. To further determine 274 the effect of $\mathrm{TcdB}^{\mathrm{FBD}}$, limiting dilution assay was employed by serial re-plating of p53/BRCA1275 deficient tumor cells at various cell concentrations in the sphere culture. The frequency of 276 sphere-forming cells, a surrogate for the frequency of TICs, was drastically reduced after $277 \mathrm{TcdB}^{\mathrm{FBD}}$ treatment, dropping from $0.42 \%(1 / 239)$ to $0.11 \%(1 / 895)$ compared to control $(P=$ 278 0.0019) (Fig. 5C). These data demonstrate that $\mathrm{TcdB}^{\mathrm{FBD}}$ targeted FZD7 ${ }^{+}$TICs and suppressed 279 their capability to generate tumorsphere in vitro.

280 To further assess the effect of $\mathrm{TcdB}^{\mathrm{FBD}}$ on TICs in vivo, we performed the limiting 281 dilution assay by transplanting $\sim 10-1,000$ p53/BRCA1-deficient tumor organoid cells to nude 282 mice. FACS analysis confirmed that most of these tumor organoid cells were FZD7 ${ }^{+}(\sim 81.7 \%$, 283 Supplementary Fig. S7D-E). TcdB ${ }^{\mathrm{FBD}}$ or TcdB ${ }^{\mathrm{mu}}$ treatment was given at $20 \mathrm{mg} / \mathrm{kg}$ twice a week 284 starting from day 5 after inoculation until day 53, when most mice had reached their endpoint 285 (Fig. 5D). Inoculating 1,000 organoid cells resulted in tumor formation in all mice within $\sim 2$ 286 weeks. Reducing the number of organoid cells decreased the chances in tumor formation, and a 287 repopulating frequency can be calculated from a serial dilution of organoid cells (Fig. 5E). $288 \mathrm{TcdB}^{\mathrm{FBD}}$ treatment reduced this frequency by 3.68 -fold from $1 / 62$ in control mice to $1 / 289.9$, 289 whereas $\mathrm{TcdB}^{\mathrm{mu}}$ treatment did not change the frequency (Fig. 5E). For instance, transplanting as 290 few as 10 transplanted cells in the control or $\mathrm{TcdB}^{\mathrm{mu}}$-treated group formed tumors 2 out of 8 291 times, whereas no tumor was detected in mice treated with $\mathrm{TcdB}^{\mathrm{FBD}}$ (Fig. 5D-E). Furthermore, 292 mice transplanted with 100 organoid cells and treated with $\mathrm{TcdB}^{\mathrm{FBD}}$ exhibited a significantly 293 longer tumor-free period than those received vehicle or $\mathrm{TcdB}^{\mathrm{mu}}$ treatment (average tumor-free 294 time 82.13 days vs. 44.37 days, $P=0.030$ ) (Fig. 5F). Consistently, mice inoculated with 10,000, 295 1,000, or 100 p53/BRCA1-deficient tumor organoid cells and treated with TcdB ${ }^{\mathrm{FBD}}$ survived 1.2 296 days $(P=0.014), 14.84$ days $(P=0.001)$, or 22.88 days $(P=0.017)$ longer than those treated 297 with vehicle or $\mathrm{TcdB}^{\mathrm{mu}}$ (Fig. 5G). Collectively, these results suggest that the inhibition of $298 \mathrm{TcdB}^{\mathrm{FBD}}$ on tumor growth is mediated by its ability to target and suppress $\mathrm{FZD}^{+} \mathrm{TICs}^{\text {in }}$ vivo. 299 
301 Even though $\mathrm{TcdB}^{\mathrm{FBD}}$ exhibited efficacy in inhibiting growth of BLBC via targeting $\mathrm{FZD}^{+}$

302 TICs, it is unlikely to eliminate tumors as a single agent. We thus examined its therapeutic value 303 in combination with a standard chemotherapy drug (e.g., cisplatin). Xenograft experiments with 304 the same initial number of tumor organoid cells from the two BLBC models (p53/BRCA1deficient and C3(1)-Tag) were engrafted in nude mice. Mice were then treated with $\mathrm{TcdB}^{\mathrm{FBD}}$ alone, cisplatin alone, or a combination of both agents following the schedule illustrated in Fig. 6A-B. TcdB ${ }^{\mathrm{FBD}}$ alone reduced tumor growth in both models and its efficacy is similar to treatment with cisplatin alone (Fig. 6A-B). Combination treatment with both $\mathrm{TcdB}^{\mathrm{FBD}}$ and cisplatin achieved the highest level of growth inhibition, close to complete suppression, than either agent alone on tumors derived from p53/BRCA1-deficient and C3(1)-Tag models, demonstrating a strong synergistic effect (Fig. 6A-B). To further confirm the synergistic effect, we also examined the sensitivity of tumor organoids of these two BL cancer models. A low concentration of cisplatin $(0.2 \mu \mathrm{M})$ did not reduce the size or number of tumor organoids, whereas combining this level of cisplatin with $\mathrm{TcdB}^{\mathrm{FBD}}$ reduced both size and number and organoids to a level lower than treatment with $\mathrm{TcdB}^{\mathrm{FBD}}$ alone (Supplementary Fig. S8). These results suggest that targeting FZD7-mediated signaling may suppress the resistance to cisplatin, or cisplatin treatment may sensitize cells to FZD7-mediated inhibition by $\mathrm{TcdB}^{\mathrm{FBD}}$. It is possible that a subpopulation of FZD7 ${ }^{+}$TIC cells are intrinsically more resistant to chemotherapy, or FZD7 is upregulated in a subpopulation of cells that developed resistance. Indeed, FACS analysis of tumor cells revealed that the percentage of $\mathrm{FZD}^{+}$cells increased after treatment with cisplatin alone in both p53/BRCA1-deficient and C3(1)-Tag models, and co-administration of $322 \mathrm{TcdB}^{\mathrm{FBD}}$ greatly reduced $\mathrm{FZD} 7^{+}$cells (Fig. 6C).

In addition to the two BL cancer models, we also tested the luminal tumor MMTV-PyMT model in xenograft models in vivo, which do not over-express $\mathrm{FZD}^{+}$and its organoids are resistant to $\mathrm{TcdB}^{\mathrm{FBD}}$ in vitro (Figs. $1 \mathrm{D}, 3 \mathrm{~A}$ ). As expected, $\mathrm{TcdB}^{\mathrm{FBD}}$ alone did not affect tumor 326 growth in this model in vivo (Fig. 6D). Surprisingly, $\operatorname{TcdB}^{\mathrm{FBD}}$ was able to synergize with 327 cisplatin in this model as well and the combination greatly suppressed tumor growth than using 328 cisplatin alone (Fig. 6D). Consistently, although neither a low concentration of cisplatin nor $329 \mathrm{TcdB}^{\mathrm{FBD}}$ alone affected tumor organoids of MMTV-PyMT model, a combination of cisplatin and $330 \mathrm{TcdB}^{\mathrm{FBD}}$ reduced the size and number of organoids (Fig. 6E-G). Thus, exposure to cisplatin may 
331 have turned the $\mathrm{TcdB}^{\mathrm{FBD}}$-insensitive tumor into a sensitive one. These findings are consistent 332 with our recent report that cisplatin treatment could lead to luminal to basal/mesenchymal cell 333 fate changes, in part due to interstrand DNA crosslinks (24). Indeed, treatment with cisplatin 334 increased expression of basal/mesenchymal genes, as well as Fzd7 in MMTV-PyMT tumors, 335 whereas these changes were reduced in the presence of $\operatorname{TcdB}^{\mathrm{FBD}}$ (Fig. $6 \mathrm{H}$ ), suggesting that 336 cisplatin-induced cell fate change renders cells to become sensitive to the co-inhibition of FZD7337 mediated Wnt signaling in luminal breast tumors. 


\section{DISCUSSION}

Wnt signaling is a key pathway in maintaining the stemness of cells. Besides well-

342 established cancer-causing mutations in Wnt pathways, recent studies have also suggested that

343 Wnt signaling upregulation contributes to many aspects of cancer development and therapy

344 resistance, including EMT, metastasis, and resistance to chemotherapy and immunotherapy, 345 properties often attributed to CSCs/TICs. Thus, Wnt signaling represents a major therapeutic 346 target in cancer treatment (15). Broadly inhibiting Wnt signaling inevitably results in side effects, 347 diminishing the therapeutic value particularly for tumors that do not carry cancer-driving 348 mutations in Wnt pathways. Inhibiting a subset of Wnt signaling may reduce the side effect and 349 it needs to be done at the ligand-receptor level as this is the most diverged node in the pathway 350 (17), but it has been difficult to develop inhibitors that can distinguish different FZD subfamily 351 members. Furthermore, whether targeting only a subset of FZDs is going to be sufficient remains 352 to be demonstrated in vivo due to concerns on potential signaling redundancy. Here we utilized 353 the natural ability of a bacterial toxin to specifically recognize FZD1, 2, 7 subgroup and 354 developed a therapeutic protein that can block FZD1/2/7-mediated Wnt signaling. We found that 355 blocking FZD1/2/7-mediated Wnt signaling reduced growth of BLBC models in vivo and also 356 synergized strongly with the traditional chemotherapy agent cisplatin in treating both BLBC and 357 luminal breast tumor models. These findings demonstrate that inhibiting a single FZD subgroup, 358 instead of pan-inhibition of Wnt signaling, is sufficient to exhibit a strong synergistic effect in 359 vivo with the standard chemotherapy, and suggest a key role of FZD1/2/7-mediated Wnt 360 signaling in the development of chemotherapy-resistance in breast cancers. Targeted inhibition 361 of this pathway could be combined with chemotherapy to eliminate/prevent therapy-resistant 362 stem cell-like cancer cells.

363 Chemotherapy remains to be the cornerstone of the first-line treatment for many tumors 364 such as BLBC/TNBC that have no suitable targeted therapy. Conventional chemotherapy is 365 effective in controlling primary tumors, but often led to a selection and/or an induction of 366 CSCs/TICs that are more resistant to these agents, leading to eventual regeneration of chemo367 resistant tumors and metastasis. Our findings that $\mathrm{TcdB}^{\mathrm{FBD}}$ synergizes strongly with cisplatin 368 treatment add to the wealth of literatures suggesting that Wnt signaling play a key role in the 369 development/selection of treatment-resistant cells and demonstrating that a combination of Wnt 
370 signaling suppression with chemotherapy is a valid strategy to eliminate CSCs/TICs at once 371 and/or prevent the emergence of therapy-induced CSCs/TICs.

372 Synergistic effect from Wnt signaling inhibition has also been reported between OMP-

373 18R5 and the chemotherapy agent taxanes on a range of tumor models (14). Future studies can 374 focus on testing whether $\mathrm{TcdB}^{\mathrm{FBD}}$ would also be effective in shrinking mammary tumors when 375 combined with other types of chemotherapeutic agents (e.g., doxorubicin) and whether combined $376 \mathrm{TcdB}^{\mathrm{FBD}}$ and cisplatin treatment could be applied to other cancer types (e.g., serous ovarian 377 cancer, oral squamous cell carcinoma). Upregulation of Wnt signaling has been associated with 378 the resistance to many common chemotherapy agents as well as radiation therapy (12). The 379 mechanistic link between Wnt signaling and therapy resistance remains to be fully established 380 and is likely multifaceted (12). For instance, recent studies suggest that Wnt signaling enhances 381 the DNA repair pathways in ovarian cancers (40), and it has been also proposed that therapy382 induced senescence promotes cancer cell stemness via Wnt signaling (41). In our study, it is 383 likely that cisplatin treatment leads to an epithelial cell fate change toward a mesenchymal state 384 (24), which may represent a dedifferentiation process that involves Wnt signaling. Lastly, Wnt 385 signaling has been shown to contribute to immune invasion as well as systemic inflammation in 386 the tumor microenvironment that drives cancer metastasis (42-45). Whether $\mathrm{TcdB}^{\mathrm{FBD}}$ may 387 provide a synergistic effect with immunotherapy such as PD-1/PD-L1 antibodies remains to be 388 explored.

389 Intestines and bones are two major tissues sensitive to disruptions in Wnt signaling 390 pathways and are often examined when testing Wnt signaling pathway inhibitors. The finding 391 that $\mathrm{TcdB}^{\mathrm{FBD}}$ did not affect intestinal tissues is consistent with previous findings that the pan392 Wnt inhibitors LGK974 did not cause any damage to the intestine until a dose much higher than 393 the therapeutic dose (33). These findings are also supported by clinical observations that 394 intestinal damage is not a major side effect in clinical trials of OMP-18R5 antibody. On the other 395 hand, bone density loss is the single most important side effect observed from clinical trials of 396 OMP-18R5. Our analysis showed that bones were not affected in mice by $\mathrm{TcdB}^{\mathrm{FBD}}$, which 397 represents a major advantage over other existing pan-Wnt signaling inhibitors and neutralizing 398 antibodies. This is possibly because both FZD7 and FZD5 are expressed in diaphyseal bone and 399 potentially play redundant roles (46). FZD5-mediated Wnt signaling in bone tissues might be 
400 sufficient to maintain bone density when FZD7 is selectively inhibited by $\mathrm{TcdB}^{\mathrm{FBD}}$, whereas the 401 neutralizing antibody OMP-18R5 inhibits both FZD1/2/7 and FZD5/8 subfamilies.

402 The specificity of $\mathrm{TcdB}^{\mathrm{FBD}}$ for FZD1/2/7 allows us to establish this agent as an effective 403 targeted therapy for FZD1/2/7 $7^{+}$TICs and cisplatin-resistant mammary tumor cells. The crystal 404 structure of $\mathrm{TcdB}^{\mathrm{FBD}}-\mathrm{CRD}$ complex showed that the toxin targets the lipid docking site in CRD. 405 The sequence variations surrounding this lipid docking site across different FZDs underlies the 406 reason for the selectivity of TcdB toward FZD1/2/7 (21,29). These data suggest that this lipid 407 docking site may serve as a promising therapeutic target for developing effective and selective 408 Wnt signaling inhibitors. Although $\mathrm{TcdB}^{\mathrm{FBD}}$ is unlikely to be effective for blocking Wnt 409 signaling in cancer cells with mutations in Wnt pathway components downstream of the receptor 410 level (e.g., CTNNB1, APC), it should be able to inhibit Wnt signaling at the level of 411 ligand/receptor interaction in cancer cells (breast cancer or other cancer types) that become 412 dependent on Wnt ligands, in a way similar to Porcupine inhibitors (37), but is more selective 413 based on utilization of specific FZD receptors (e.g., FZD7) and is less toxic to normal tissues 414 (e.g., bone). These properties make this bacterial toxin-derived molecule a highly promising 415 agent for targeting FZD1/2/7-mediated Wnt signaling in vivo for cancer treatment. 


\section{METHODS}

418 Cloning, expression, and purification of recombinant proteins. The gene encoding $\mathrm{TcdB}^{\mathrm{FBD}}$ 419 (residues 1285-1804) was cloned into pET28a vector, with an N-terminus HA tag. Mutated $420 \mathrm{TcdB}^{\mathrm{FBD}}$ variants $\left(\mathrm{TcdB}^{\mathrm{mu}}\right)$ were generated by two-step PCR and verified by DNA sequencing. $421 \mathrm{TcdB}^{\mathrm{FBD}}$ and $\mathrm{TcdB}^{\mathrm{mu}}$ were expressed in E. coli strain BL21-Star (DE3) (Invitrogen). Bacteria 422 were cultured at $37^{\circ} \mathrm{C}$ in $\mathrm{LB}$ medium containing kanamycin. The temperature was reduced to $42316^{\circ} \mathrm{C}$ when OD600 reached $\sim 0.8$. Expression was induced with $1 \mathrm{mM}$ IPTG (isopropyl-b-D424 thiogalactopyranoside) and continued at $16^{\circ} \mathrm{C}$ overnight. Proteins were purified using Ni2+-NTA 425 (nitrilotriacetic acid, Qiagen) affinity resins in a buffer containing $40 \mathrm{mM}$ imidazole, $400 \mathrm{mM}$ $426 \mathrm{NaCl}$, and $50 \mathrm{mM}$ Tris $\mathrm{pH}$ 8.0. The proteins were eluted with a high-imidazole buffer $(300 \mathrm{mM}$ 427 imidazole, $400 \mathrm{mM} \mathrm{NaCl}$, and $50 \mathrm{mM}$ Tris, $\mathrm{pH} \mathrm{8.0)}$ and then dialyzed at $4^{\circ} \mathrm{C}$ against a buffer 428 containing $150 \mathrm{mM} \mathrm{NaCl}$ and $20 \mathrm{mM}$ HEPES, pH 7.5. Proteins were further purified by MonoQ 429 ion-exchange (20 mM Tris, $\mathrm{pH}$ 8.5) and Superdex-200 size-exclusion chromatography (GE 430 Healthcare, $20 \mathrm{mM}$ Tris, $\mathrm{pH} 8.0$, and $100 \mathrm{mM} \mathrm{NaCl}$ ). Proteins were further incubated with 431 Endotoxin Removal Resin (Thermo Scientific, \# 88270) at $4{ }^{\circ} \mathrm{C}$ with gentle mixing for $1 \mathrm{~h}$ in 432 columns, collected by centrifugation, further concentrated to $\sim 10 \mathrm{mg} / \mathrm{ml}$ in PBS, and stocked in 433 aliquots at $-80^{\circ} \mathrm{C}$.

Cell lines and constructs. MB-MDA-231 (\# HTB-26), MCF7 (\# HTB-22), U2OS (\# HTB-96), 436293 (\#CRL-3216), HPAF-II (\#CRL-1997), L cells (\#CRL-2648), and L/WNT3A (\#CRL-2647) 437 cells were originally obtained from ATCC. PaTu8988s was generously provided by Stephane 438 Angers (University of Toronto, Canada). The cells were cultured in DMEM medium 439 supplemented with $10 \%$ fetal bovine serum, 10,000 I.U./mL Penicillin, $50 \mu \mathrm{g} / \mathrm{ml}$ streptomycin 440 (Invitrogen) in a humidified atmosphere containing $5 \% \mathrm{CO}_{2}$ at $37{ }^{\circ} \mathrm{C}$. Stable Wnt-reporter cells 441 (MB-MDA-231-TK/RL, U2OS-TK/RL, 293T-TK/RL cells) were generated by lentiviral 442 transduction of MB-MDA-231, U2OS, 293T cells with constructs expressing Renilla and firefly 443 luciferases (7xTcf-FFluc, \# 24308; RLUC - IRES - FLUC, \# 45642, Addgene), followed by 444 selection with $3 \mu \mathrm{g} / \mathrm{ml}$ puromycin and $50 \mu \mathrm{g} / \mathrm{ml}$ geneticin.

446 Preparation of WNT3A-conditioned induction medium. WNT3A-conditioned induction 447 medium was generated using L-WNT3A cells according to the manufacturer's protocol. 
448 Conditioned medium from the corresponding L-cells was collected and used as a control. Briefly,

449 the cells were grown in $10 \mathrm{~mL}$ of DMEM supplemented with $10 \%$ FBS for 4 days prior to 450 collecting conditioned medium. To these cells, another $10 \mathrm{~mL}$ of fresh medium was added and 451 cultured for 3 days to collect second batch of conditioned medium. The two batches of 452 conditioned media were mixed at a $1: 1$ ratio and filtered using $0.22 \mu \mathrm{m}$ filter and stored at $4{ }^{\circ} \mathrm{C}$ 453 until usage.

455 Wnt signaling assay. The TOPFLASH/TK-Renilla dual luciferase reporter assay (\# E1910, 456 Promega) was used to detect Wnt signaling activities. Briefly, Wnt signaling activates expression 457 of TOPFLASH luciferase reporter (firefly luciferase), Renilla luciferase serves as an internal 458 control. To obtain Wnt signaling inhibition dose response curve for $\mathrm{TcdB}^{\mathrm{FBD}}$ in Wnt reporter 459 cells, MB-MDA-231- TK/RL, U2OS- TK/RL, 293T- TK/RL cells in 24-well plates were treated 460 with a range of concentrations of $\mathrm{TcdB}^{\mathrm{FBD}}$ with 10 doses in 2-fold dilution series in WNT3A461 conditional medium for $6 \mathrm{~h}$. GraphPad Prism software was used for graphing and 462 EC50 calculations.

464 Viability assay for cell lines. MB-MDA-231, MCF7, U2OS, 293T Cells were seeded at 30004655000 cells per well in 96-well plates. Twenty-four $\mathrm{h}$ after seeding, cells were treated with $466 \mathrm{TcdB}^{\mathrm{FBD}}$ in triplicates, with 10 doses in 2-fold dilution for $72 \mathrm{~h}$, the MTT solution was added to 467 the culture medium $(500 \mu \mathrm{g} / \mathrm{ml})$. After incubation at $37^{\circ} \mathrm{C}$ for $3 \mathrm{~h}$, followed by the addition of $468200 \mu \mathrm{l}$ of dimethylsulfoxide (DMSO) to solubilize MTT. The absorbance at $562 \mathrm{~nm}$ was 469 measured on a microplate reader. Normal cells without exposure to $\mathrm{TcdB}^{\mathrm{FBD}}$ were considered as $470100 \%$ viable.

471

472 Colony formation assay. HPAF-II and PaTu8988s cells were seeded in 24-well plates at a 473 density of 2000 cells per well, and cultured in the culture medium added with 100 nM LGK974 474 or $150 \mathrm{nM} \mathrm{TcdB}{ }^{\mathrm{FBD}}$ or PBS vehicle control for 11 days and medium was refreshed every three 475 days. Cells were washed by PBS, fixed by $4 \%$ paraformaldehyde for 15 min, stained with $0.5 \%$ 476 crystal violet for $1 \mathrm{~h}$, washed three times by $\mathrm{ddH}_{2} \mathrm{O}$ and then photographed with a digital camera. 477 The number of colonies was counted. 
479 Mouse models. The C3(1)-Tag transgenic mice (FVB-Tg(C3-1-TAg)cJeg/JegJ, Stock No: 480 013591), MMTV-PyMT (FVB/N-Tg(MMTV-PyMT)634Mul/J, Stock No: 002374), $481 \operatorname{Trp}^{L} 3^{L}\left(\mathrm{~B} 6.129 \mathrm{P} 2-\operatorname{Trp} 53^{\text {tmlBrn}} / \mathrm{J}\right.$, Stock No: 008462), Brcal ${ }^{L}$ (STOCK Brcal ${ }^{\text {tmlAash }} / \mathrm{J}$, Stock

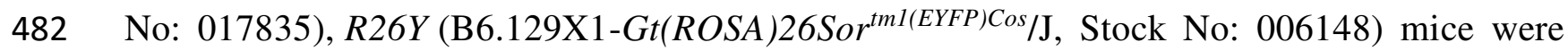
483 obtained from The Jackson Laboratory. To target luminal MECs in Trp5 $3^{L / L} ;$ Brcal $^{L / L} ; R 26 Y$ 484 adult female mice (2-3 months of age) were anaesthetized; and Ad-K8-Cre adenovirus 485 (diluted in 0.1\% Bromophenol blue in DMEM) was introduced into ducts of the fourth 486 mammary gland via intraductal injection(47). Mice were then monitored via palpation or 487 visual inspection weekly for tumor appearance. Once tumors were detected, animals were 488 monitored three times a week for tumor development. For xenograft studies, six-eight weeks 489 old female nude mice (Hsd: Athymic Nude-Foxn $1^{n u}$, 6903F) were purchased from Envigo RMS, 490 Inc (Indianapolis, IN 46250 USA). All animal experiments were approved by the Institutional 491 Animal Care and Use Committee (IACUC) of the Brigham and Women's Hospital and 492 Boston Children's Hospital where these mice were housed.

Tumor dissociation. Mammary tumors from the above mice were harvested, dissected and minced, and then incubated in digestion medium (2\% Penicillin/Streptomycin, $0.1 \mathrm{mg} / \mathrm{ml}$ 496 Gentamicin, 0.6\% Nystatin, $2 \mathrm{mg} / \mathrm{ml}$ Collagenase A, $0.096 \mathrm{mg} / \mathrm{ml}$ Hyaluronidase in DMEM/F12) 497 at $37^{\circ} \mathrm{C}$ with shaking for $2 \mathrm{~h}$. After digestion, the cells/tissues were treated sequentially with $4980.25 \%$ trypsin/EDTA $\left(37^{\circ} \mathrm{C}, 2 \mathrm{~min}\right), 5 \mathrm{mg} / \mathrm{ml}$ dispase with DNaseI $(0.1 \mathrm{mg} / \mathrm{ml}$, Sigma, St Louis, $499 \mathrm{MO} ; 37^{\circ} \mathrm{C}, 5 \mathrm{~min}$ ), cold red blood cell (RBC) lysis buffer (2-3 min). Between each treatment 500 step, cells/tissues were washed with PBS. After treatment with the RBC lysis buffer, cells/tissues 501 were filtered through $40 \mathrm{~mm}$ cell strainer to obtain single-cell suspension.

503 Organoid Culture. 2000 single cells digested from the corresponding primary tumors were 504 seeded in $20 \mu 1$ Matrigel in a 48-well-plate, cultured in $250 \mu \mathrm{l}$ DMEM/F12 supplemented with 12 505 mM Hepes, 1\% GlutaMAX, 1:50 B27, $0.21 \mu \mathrm{g} / \mathrm{mL}$ A83-01, $0.1 \mu \mathrm{g} / \mathrm{ml}$ EGF, $10 \mu \mathrm{M}$ Y-27632,100 $506 \mathrm{ng} / \mathrm{ml}$ Noggin and $0.6 \mu \mathrm{g} / \mathrm{ml} \mathrm{R}$-spondin1. Established clonal organoids were trypsinized using 507 TrypLE (Thermo Fisher Scientific). $\mathrm{TcdB}^{\mathrm{FBD}}$ or $\mathrm{TcdB}^{\mathrm{mu}}(150 \mathrm{nM})$ was added to the culture 508 medium every day, PBS was used as a vehicle control. 
510 Tumor implantation and evaluation. To establish xenograft tumors, a single p53/BRCA1 511 deficient tumor organoid cell suspension was harvested after trypsinization. The cells were 512 resuspended in DMEM and Matrigel $(\mathrm{V}: \mathrm{V}=1: 1)$ and then were injected into the flank of nude 513 mice. Tumors could be observed 5-7 days after organoid cell inoculation $\left(1 \times 10^{4}\right)$, tumor 514 volumes were measured, and the mice were weighed twice weekly. Tumor volume was 515 calculated using the formula: $1 / 2$ (Length $\times$ Width $^{2}$ ). When tumors reach $\sim 50 \mathrm{~mm}^{3}(\sim 9$ days post 516 inoculation of $\left.1 \times 10^{4}\right)$ mice were randomly divided into four groups ( 8 or 10 mice/group) and 517 the mean tumor volumes of each group were similar. No mice were excluded during the 518 treatment. Each group received one of the following treatments: PBS $(150 \mu \mathrm{L} /$ mice $)$, endo-toxin 519 free $\operatorname{TcdB}^{\mathrm{FBD}}(20,50,100 \mathrm{mg} / \mathrm{kg})$, or $\mathrm{TcdB}^{\mathrm{mu}}$, once a day on day $9,12,14,17,20$, and 23 post 520 inoculation via intraperitoneal injection (i.p.). For combination treatment, Each group received 521 one of the following treatments: PBS $(150 \mu \mathrm{L} / \mathrm{mice})$, cisplatin $(5 \mathrm{mg} / \mathrm{kg})$ alone or with endo522 toxin free $\mathrm{TcdB}^{\mathrm{FBD}}(20 \mathrm{mg} / \mathrm{kg})$ once a day on the indicated day post inoculation via 523 intraperitoneal injection (i.p.).

Bioluminescent assay. MDA-MB-231 cells that express integrated TOPFLASH were 526 subcutaneously injected into immune-deficient athymic nude mice, when tumor length reached $52710 \mathrm{~mm}, \mathrm{TcdB}^{\mathrm{FBD}}$ or $\mathrm{TcdB}^{\mathrm{mu}}$ was injected at $20 \mathrm{mg} / \mathrm{kg}$ dose at indicated time. Five minutes before 528 sacrifice, $100 \mathrm{mg} / \mathrm{kg}$ D-Luciferin was given (i.p.), tumors were dissected, put into 24-plate, and 529 bioluminescent imaging were examined using a Xenogen IVIS-200 system (Xenogen). Images 530 were analyzed by quantification of total photon flux of each tumor using Living Imaging 531 Software. The p53/BRCA1-deficient tumor organoid cells were transduced by lentivirus with 532 constructs 7xTcf-FFluc and subjected to the same analysis as described for MDA-MB-231 cells.

534 TcdB $^{\mathrm{FBD}}$ in vivo toxicity assay or EdU staining. Six weeks old female nude mice were injected 535 (i.p.) with the $\mathrm{TcdB}^{\mathrm{FBD}}(20,50$, or $100 \mathrm{mg} / \mathrm{kg})$ or $\mathrm{TcdB}^{\mathrm{mu}}(20 \mathrm{mg} / \mathrm{kg})$ twice a week for five 536 weeks. Mice were injected intraperitoneally (i.p.) once with EdU at the dose of $100 \mathrm{mg} / \mathrm{kg}$ body 537 weight $12 \mathrm{~h}$ before euthanization. Intestine tissues were cleaned with cold PBS, fixed in $4 \%$ 538 formaldehyde, and embedded in paraffin. Four- $\mu$ m-thick sections were prepared, and the 539 intestine crypt proliferation was conducted using Click-iT ${ }^{\circledR}$ EdU Alexa Fluor ${ }^{\circledR} 594$ Imaging Kit 540 (C10339, Invitrogen) according to manufacturer's introduction. Briefly, the sections were 
541 washed twice with 3\% BSA in PBS and permeabilized in $0.5 \%$ Triton $^{\circledR} \mathrm{X}-100$, then incubated 542 with a Click-iT ${ }^{\mathrm{TM}}$ reaction cocktail, followed by incubation in $5 \mu \mathrm{g} / \mathrm{mL}$ Hoechst 33342 according 543 to the manufacturer's protocol.

545 Micro-computed tomography $(\boldsymbol{\mu C T})$. The right femur was extracted at euthanization and fixed 546 in 4\% paraformaldehyde for 2 days, then transferred into 70\% ethanol. A 2.6-mm span of the 547 distal femoral metaphysis was scanned on a desktop $\mu \mathrm{CT}$ ( $\mu$ CT-35; Scanco Medical AG) at 10$548 \mu \mathrm{m}$ resolution using $50-\mathrm{kV}$ peak tube potential and 151-ms integration time to 549 measure cancellous three-dimensional morphometric properties as previously described(48). 550 Standard trabecular bone parameters (BV/TV, Tb.N, Tb.Th) were calculated from each 551 reconstructed stack through the metaphysis. Cortical thickness $(\mathrm{Ct}$. Th) and area $(\mathrm{Ct}$.Ar) were 552 obtained from 20 slices reconstructed through the midshaft femur.

554 Immunofluorescence staining. Immunofluorescence (IF) staining was performed on tissue 555 sections that were fixed in $10 \%$ formalin (Fisher Scientific, Hampton, NH) and embedded in 556 paraffin. Antigen retrieval (Citrate buffer $\mathrm{pH}$ 6.0, $20 \mathrm{~min}$ boil in microwave oven) was 557 performed before blocking and endogenous peroxidase activity was quenched on the slides 558 intended for IF by incubation in $0.3 \% \mathrm{H}_{2} \mathrm{O}_{2}$. Antibodies included: LEF1 (clone C12A5, \#2230; 559 Cell Signaling;1:100), active $\beta$-catenin (clone D13A1, \#8814; Cell Signaling;1:100).

561 Flow cytometry. Flow cytometric (FACS) analysis was performed after single cells were 562 obtained using an Accuri C6 analyzer (BD Biosciences, San Jose, CA) and analyzed with CFlow 563 software (BD Biosciences). The following antibodies were utilized: CD24 (clone M1/69, 564237; 564 BD Biosciences; 1:100), CD29 (clone eBioHMb1-1, 12-0291-82; 1:250), FITC-TcdB ${ }^{\text {FBD }}(0.1$ 565 mg/ml), FZD7 (Clone 151143, FAB1981A; RD system; 1:100), CD31 (clone 390, 13-0311-85; 566 eBioscience 1:100), CD45 (clone 30-F11, 13-0451-82; eBioscience; 1:100) and TER119 (clone 567 Ter-119, 13-5921-85; eBioscience; 1:100).

569 Tumorsphere formation and $e x$ vivo tumorigenicity assays. Single cells obtained from cell 570 lines or tumor tissues were resuspended and plated into round-bottom 96-well ultralow 571 attachment plates (Corning) at a density of 1, 5, 10, 100, and 200 cells per well, or at 5000 cells 
572 per well in 24-well flat-bottom ultralow attachment plates in the sphere culture medium

573 (DMEM/F12 media supplemented with B27 (100 units/mL), Insulin (10 $\mu \mathrm{g} / \mathrm{mL})$, EGF (20

$574 \mathrm{ng} / \mathrm{mL})$ and bFGF (20 ng/mL) with $150 \mathrm{nM} \mathrm{TcdB}{ }^{\mathbf{F B D}}$ or TcdB ${ }^{\mathrm{mu}}$, PBS served as control. The

575 frequency of TICs was calculated using the ELDA website

576 (http://bioinf.wehi.edu.au/software/elda/index.html). The tumorsphere formation frequency in

577 24-well plates was calculated according to the formula F= Numbers of forming tumorspheres /

578 Number of single cells plated. For secondary and tertiary tumorsphere formation, single cell

579 suspensions prepared from the previous generation of tumorspheres were re-plated under the

580 same conditions as the first generation.

582 In vivo tumorigenicity assay. p53/BRCA1-deficient tumor organoid cells (10, 100, or 1000 583 cells) were injected subcutaneously into nude mice in serum-free DMEM/Matrigel. The growth 584 of tumor was evaluated daily over a 3-month period. The animal ethics endpoint was tumor 585 reaching a size of $10 \mathrm{~mm}$. Tumor volume was monitored and calculated as described above. The 586 TIC frequency was derived as described above. For the Kaplan-Meier tumor free survival curves, 587 mice were considered tumor free until tumors were visible or palpable. For the Kaplan-Meier 588 survival curves, mice were considered alive until tumors reach ethics endpoint a size of $10 \mathrm{~mm}$.

Reverse transcription and quantitative real-time PCR. Total RNAs from tumors were 591 purified by either Trizol or the Allprep DNA/RNA mini kit (Qiagen). cDNA was generated with 592 iScript (Bio-Rad, Berkeley, CA) according to the manufacturer's protocol. Quantitative RT-PCR 593 (qRT-PCR, for RNA) and PCR (for genomic DNA) were performed using FastStart SYBR 594 Green Master (Roche, Indianapolis, IN). PCR primers are listed below:

595 FZD1:forward:5'-GAGTTCTGGACCAGTAATCCGC-3';reverse:5'-

596 ATGAGCCCGTAAACCTTGGTG-3'; FZD2: forward: 5'-CTTCTCGCAAGAGGAGACTCG597 3'; reverse: 5'-GTGGTGACCGTGAAGAAAGTG-3'; FZD3: forward: 5'598 ATGGCTGTGAGCTGGATTGTC-3'; reverse: 5'-GGCACATCCTCAAGGTTATAGGT-3'; 599 FZD4: forward: 5'-AACCTCGGCTACAACGTGAC-3'; 600 GGCACATAAACCGAACAAAGGAA-3'; FZD5: forward: 5'601 GGTGTGCCAGGAAATCACG-3'; reverse: 5'-CACAAGCGGCCAGAATTGG-3'; FZD6: 602 forward: 5'-TCTGCCCCTCGTAAGAGGAC-3'; 
604 GCCACACGAACCAAGAGGAC-3'; reverse: 5'-CGGGTGCGTACATAGAGCATAA-3'; 605 FZD8: forward: 5'-GGGTTACCTGTTGGAAGTGAC-3'; reverse: 5'606 GGCACCGTGATCTCTTGGC-3'; FZD9: forward: 5'-CGCACGCACTCTGTATGGAG-3'; 607 reverse: 5'-GCCGAGACCAGAACACCTC-3'; FZDI0: forward: 5'608 CATGCCCAACCTGATGGGTC-3'; reverse: 5'-GCCACCTGAATTTGAACTGCTC-3'; 609 Gapdh: forward: 5'-GGTGAAGGTCGGTGTGAACG-3'; reverse: 5'610 CTCGCTCCTGGAAGATGGTG-3'; Axin2: forward: 5'-ATGAGTAGCGCCGTGTTAGTG-3'; 611 reverse: 5'- GGGCATAGGTTTGGTGGACT -3'; Vim: forward: 5'612 CGGCTGCGAGAGAAATTGC-3'; reverse: 5'-CCACTTTCCGTTCAAGGTCAAG-3'; Zeb1: 613 forward: 5'-GCTGGCAAGACAACGTGAAAG-3'; reverse: 614 GCCTCAGGATAAATGACGGC-3'; Rnf43: forward: 5'-CACGAGTTTCATCGAACGTGT-3'; 615 reverse: 5'-CTGGCGAATGAGGTGGAGT-3'.

616 Viability assay for human breast cancer organoids. Organoid lines derived from breast cancer 617 patients are identified, as previously reported(34). 74T was a luminal organoid line and 86T was 618 a basal-like line. The organoid was cultured in $250 \mu \mathrm{l}$ DMEM/F12 supplemented with $10 \mathrm{mM}$ 619 Hepes, $50 \mu \mathrm{g} / \mathrm{ml}$ Primocin, 1\% GlutaMAX, 1:50 B27, 1mM N-Acetylcysteine, $50 \mathrm{ng} / \mathrm{ml}$ EGF, $62020 \mathrm{ng} / \mathrm{ml}$ FGF 2, $10 \mu \mathrm{M}$ Y-27632, $100 \mathrm{ng} / \mathrm{ml}$ Noggin. $\operatorname{TcdB}^{\mathrm{FBD}}$ or TcdB ${ }^{\mathrm{mu}}(150,300,500,1000$ $621 \mathrm{nM}$ ) was added to the culture medium every day for 10 days, PBS was used as a vehicle control. 622 The viability of organoids was assessed using the CellTiter-Glo luminescent cell viability assay 623 (\# G7570, Promega) according to the manufacturer's protocol.

625 Immunoblot. Tumor tissues were lysed by RIPA buffer (50 mM Tris, $1 \%$ NP40, $150 \mathrm{mM} \mathrm{NaCl}$, $6260.5 \%$ sodium deoxycholate, $0.1 \%$ SDS) with protease inhibitor cocktail (Roche). Total proteins 627 were loaded on SDS-PAGE and transferred to PVDF membrane. After blocking, proteins were 628 detected with a 1:1000 dilution of primary antibody active $\beta$-catenin (clone D13A1, \#8814; Cell 629 Signaling;1:1000) using the enhanced chemiluminescence (ECL) method (Pierce). 
633 Statistical analysis. All statistical analyses were performed using GraphPad Prism 6.0 (San 634 Diego, CA). An unpaired t test was used for comparisons between two experimental groups, and 635 ANOVA was used for comparisons of more than two groups. Unless otherwise indicated, all 636 results were averaged from biological triplicates and values are reported as means \pm s.e.m. $P<$ 6370.05 was considered statistically significant.

638

639 
641 We thank members of the Dong lab and Dr. Matthew L. Warman (Boston Children's Hospital / 642 Harvard Medical School) for discussion, suggestions, and comments. This study was partially 643 supported by NIH grants (R01AI132387, R01AI139087, R21CA235533) to M.D.; Breakthrough 644 Award from Department of Defense (W81XWH-18-1-0037) and NIH grant (R01CA222560) to 645 Z.L.; NIH grants (R01AI139087, R01AI125704, R21AI123920, and R21AI139690) to R.J.. A.H. 646 is supported by St. Baldrick's Foundation (585350) and Natural Science Foundation of Shanghai, 647 China (16ZR1425900). M.D. acknowledges support by the NIH-funded Harvard Digestive 648 Disease Center (P30DK034854) and Boston Children's Hospital Intellectual and Developmental 649 Disabilities Research Center (P30HD18655). M.D. holds the Investigator in the Pathogenesis of 650 Infectious Disease award from the Burroughs Wellcome Fund.

651

\section{Authors' Contributions}

653 Conception and design: A.H., D.X., M.D., R.J., and Z.L.

654 Development of methodology: A.H., D.X, Z.L.

655 Acquisition of data: A.H., D.X., O.K., H.C., D.J.H., A.G.R., R.T.B.,

656 Analysis and interpretation of data (e.g., statistical analysis, biostatistics, computational analysis):

657 R.S., X.H., L.S., K.Z., D.X., Y.H., Z.S.

658 Writing, review, and/or revision of the manuscript: A.H., D.X., M.D., Z.L.

659 Administrative, technical, or material support (i.e., reporting or organizing data, constructing 660 databases): P.C., R.J., R.S., X.H.

661 Study supervision: M.D., Z.L.

662

\section{Conflicts of Interest}

664 A patent application on utilizing TcdB fragments for inhibiting Wnt signaling has been filed by 665 Boston Children's Hospital, with M.D., R.J., L.T., A.H., and P.C. as inventors.

\section{Data Availability Statement}

All data is available in the main text or supplementary materials. All materials created in 669 this study are available with material transfer agreements approved by Boston Children's 670 Hospital to any researcher for purposes of reproducing or extending the analysis. 


\section{References}

676 1. Perou CM, Sorlie T, Eisen MB, van de Rijn M, Jeffrey SS, Rees CA, et al. Molecular

677 portraits of human breast tumours. Nature 2000;406(6797):747-52 doi 10.1038/35021093.

678 2. Sorlie T, Perou CM, Tibshirani R, Aas T, Geisler S, Johnsen H, et al. Gene expression 679 patterns of breast carcinomas distinguish tumor subclasses with clinical implications. Proc Natl Acad Sci U S A 2001;98(19):10869-74.

3. Pal SK, Childs BH, Pegram M. Triple negative breast cancer: unmet medical needs. Breast Cancer Res Treat 2011;125(3):627-36 doi 10.1007/s10549-010-1293-1.

4. Comprehensive molecular portraits of human breast tumours. Nature 2012;490(7418):6170.

5. Sorlie T, Perou CM, Tibshirani R, Aas T, Geisler S, Johnsen H, et al. Gene expression patterns of breast carcinomas distinguish tumor subclasses with clinical implications. Proc Natl Acad Sci U S A 2001;98(19):10869-74.

6. Tran B, Bedard PL. Luminal-B breast cancer and novel therapeutic targets. Breast Cancer Res 2011;13(6):221 doi 10.1186/bcr2904.

7. Shaked Y. The pro-tumorigenic host response to cancer therapies. Nat Rev Cancer 2019;19(12):667-85 doi 10.1038/s41568-019-0209-6.

8. Lytle NK, Barber AG, Reya T. Stem cell fate in cancer growth, progression and therapy resistance. Nat Rev Cancer 2018;18(11):669-80 doi 10.1038/s41568-018-0056-X.

9. Nusse R, Clevers H. Wnt/beta-Catenin Signaling, Disease, and Emerging Therapeutic Modalities. Cell 2017;169(6):985-99 doi S0092-8674(17)30547-0

10. Zhan T, Rindtorff N, Boutros M. Wnt signaling in cancer. Oncogene 2017;36(11):146173 doi 10.1038/onc.2016.304

11. Gujral TS, Chan M, Peshkin L, Sorger PK, Kirschner MW, MacBeath G. A noncanonical Frizzled2 pathway regulates epithelial-mesenchymal transition and metastasis. Cell 2014;159(4):844-56 doi 10.1016/j.cell.2014.10.032

12. Zhong Z, Virshup DM. Wnt Signaling and Drug Resistance in Cancer. Mol Pharmacol 2020;97(2):72-89 doi 10.1124/mol.119.117978

13. Khramtsov AI, Khramtsova GF, Tretiakova M, Huo D, Olopade OI, Goss KH. Wnt/betacatenin pathway activation is enriched in basal-like breast cancers and predicts poor outcome. Am J Pathol 2010;176(6):2911-20.

14. Gurney A, Axelrod F, Bond CJ, Cain J, Chartier C, Donigan L, et al. Wnt pathway inhibition via the targeting of Frizzled receptors results in decreased growth and tumorigenicity of human tumors. Proc Natl Acad Sci U S A 2012;109(29):11717-22 doi 10.1073/pnas.1120068109.

15. Krishnamurthy N, Kurzrock R. Targeting the Wnt/beta-catenin pathway in cancer: Update on effectors and inhibitors. Cancer Treat Rev 2018;62:50-60 doi S03057372(17)30187-1 [pii]

16. Alexander CM. The Wnt Signaling Landscape of Mammary Stem Cells and Breast Tumors. Prog Mol Biol Transl Sci 2018;153:271-98 doi S1877-1173(17)30198-9 [pii] 
17. MacDonald BT, He X. Frizzled and LRP5/6 receptors for Wnt/beta-catenin signaling. Cold Spring Harb Perspect Biol 2012;4(12) doi 10.1101/cshperspect.a007880.

18. Kahn M. Can we safely target the WNT pathway? Nat Rev Drug Discov 2014;13(7):51332 doi 10.1038/nrd4233

19. Le PN, McDermott JD, Jimeno A. Targeting the Wnt pathway in human cancers: therapeutic targeting with a focus on OMP-54F28. Pharmacol Ther 2015;146:1-11 doi 10.1016/j.pharmthera.2014.08.005

20. Tao L, Zhang J, Meraner P, Tovaglieri A, Wu X, Gerhard R, et al. Frizzled proteins are colonic epithelial receptors for C. difficile toxin B. Nature 2016;538(7625):350-5 doi 10.1038/nature19799

21. Chen P, Tao L, Wang T, Zhang J, He A, Lam KH, et al. Structural basis for recognition of frizzled proteins by Clostridium difficile toxin B. Science 2018;360(6389):664-9 doi 10.1126/science.aar1999

22. Bennett CN, Tomlinson CC, Michalowski AM, Chu IM, Luger D, Mittereder LR, et al. Cross-species genomic and functional analyses identify a combination therapy using a CHK1 inhibitor and a ribonucleotide reductase inhibitor to treat triple-negative breast cancer. Breast Cancer Res 2012;14(4):R109 doi 10.1186/bcr3230.

23. Pfefferle AD, Herschkowitz JI, Usary J, Harrell JC, Spike BT, Adams JR, et al. Transcriptomic classification of genetically engineered mouse models of breast cancer identifies human subtype counterparts. Genome Biol 2013;14(11):R125 doi 10.1186/gb2013-14-11-r125.

24. Wang H, Xiang D, Liu B, He A, Randle HJ, Zhang KX, et al. Inadequate DNA Damage Repair Promotes Mammary Transdifferentiation, Leading to BRCA1 Breast Cancer. Cell 2019;178(1):135-51 e19 doi 10.1016/j.cell.2019.06.002.

25. Tao L, van Bragt MPA, Laudadio E, Li Z. Lineage Tracing of Mammary Epithelial Cells Using Cell-Type-Specific Cre-Expressing Adenoviruses. Stem Cell Reports 2014;2(6):770-9 doi http://dx.doi.org/10.1016/j.stemcr.2014.04.004.

26. Lim E, Vaillant F, Wu D, Forrest NC, Pal B, Hart AH, et al. Aberrant luminal progenitors as the candidate target population for basal tumor development in BRCA1 mutation carriers. Nat Med 2009;15(8):907-13 doi nm.2000 [pii]

27. Molyneux G, Geyer FC, Magnay FA, McCarthy A, Kendrick H, Natrajan R, et al. BRCA1 basal-like breast cancers originate from luminal epithelial progenitors and not from basal stem cells. Cell Stem Cell 2010;7(3):403-17 doi S1934-5909(10)00346-2 [pii]

28. Proia TA, Keller PJ, Gupta PB, Klebba I, Jones AD, Sedic M, et al. Genetic predisposition directs breast cancer phenotype by dictating progenitor cell fate. Cell Stem Cell 2011;8(2):149-63 doi S1934-5909(10)00702-2 [pii]

29. Chen P, Tao L, Liu Z, Dong M, Jin R. Structural insight into Wnt signaling inhibition by Clostridium difficile toxin B. FEBS J 2019;286(5):874-81 doi 10.1111/febs.14681.

30. Yang L, Wu X, Wang Y, Zhang K, Wu J, Yuan YC, et al. FZD7 has a critical role in cell proliferation in triple negative breast cancer. Oncogene 2011;30(43):4437-46 doi 10.1038/onc.2011.145

31. Tao L, Tian S, Zhang J, Liu Z, Robinson-McCarthy L, Miyashita SI, et al. Sulfated glycosaminoglycans and low-density lipoprotein receptor contribute to Clostridium difficile toxin A entry into cells. Nat Microbiol 2019;4(10):1760-9 doi 10.1038/s41564019-0464-z 
32. Steinhart Z, Pavlovic Z, Chandrashekhar M, Hart T, Wang X, Zhang X, et al. Genomewide CRISPR screens reveal a Wnt-FZD5 signaling circuit as a druggable vulnerability of RNF43-mutant pancreatic tumors. Nat Med 2017;23(1):60-8 doi 10.1038/nm.4219.

33. Liu J, Pan S, Hsieh MH, Ng N, Sun F, Wang T, et al. Targeting Wnt-driven cancer through the inhibition of Porcupine by LGK974. Proc Natl Acad Sci U S A 2013;110(50):20224-9 doi 10.1073/pnas.1314239110

34. Sachs N, de Ligt J, Kopper O, Gogola E, Bounova G, Weeber F, et al. A Living Biobank of Breast Cancer Organoids Captures Disease Heterogeneity. Cell 2018;172(1-2):373-86 e10 doi S0092-8674(17)31319-3 [pii]

35. Flanagan DJ, Phesse TJ, Barker N, Schwab RH, Amin N, Malaterre J, et al. Frizzled7 functions as a Wnt receptor in intestinal epithelial Lgr5(+) stem cells. Stem Cell Reports 2015;4(5):759-67 doi 10.1016/j.stemcr.2015.03.003

36. Gregorieff A, Clevers H. Wnt signaling in the intestinal epithelium: from endoderm to cancer. Genes Dev 2005;19(8):877-90 doi 10.1101/gad.1295405.

37. Madan B, McDonald MJ, Foxa GE, Diegel CR, Williams BO, Virshup DM. Bone loss from Wnt inhibition mitigated by concurrent alendronate therapy. Bone Res 2018;6:17 doi 10.1038/s41413-018-0017-8.

38. Shaw FL, Harrison H, Spence K, Ablett MP, Simoes BM, Farnie G, et al. A detailed mammosphere assay protocol for the quantification of breast stem cell activity. J Mammary Gland Biol Neoplasia 2012;17(2):111-7 doi 10.1007/s10911-012-9255-3.

39. Lombardo Y, de Giorgio A, Coombes CR, Stebbing J, Castellano L. Mammosphere formation assay from human breast cancer tissues and cell lines. J Vis Exp 2015(97) doi 10.3791/52671.

40. Yamamoto TM, McMellen A, Watson ZL, Aguilera J, Ferguson R, Nurmemmedov E, et al. Activation of Wnt signaling promotes olaparib resistant ovarian cancer. Mol Carcinog 2019;58(10):1770-82 doi 10.1002/mc.23064.

41. Milanovic M, Fan DNY, Belenki D, Dabritz JHM, Zhao Z, Yu Y, et al. Senescenceassociated reprogramming promotes cancer stemness. Nature 2018;553(7686):96-100 doi 10.1038/nature25167

42. Wang B, Tian T, Kalland KH, Ke X, Qu Y. Targeting Wnt/beta-Catenin Signaling for Cancer Immunotherapy. Trends Pharmacol Sci 2018;39(7):648-58 doi S01656147(18)30060-9

43. Spranger S, Bao R, Gajewski TF. Melanoma-intrinsic beta-catenin signalling prevents anti-tumour immunity. Nature 2015;523(7559):231-5 doi 10.1038/nature14404

44. Castagnoli L, Cancila V, Cordoba-Romero SL, Faraci S, Talarico G, Belmonte B, et al. WNT signaling modulates PD-L1 expression in the stem cell compartment of triplenegative breast cancer. Oncogene 2019;38(21):4047-60 doi 10.1038/s41388-019-0700-2

45. Wellenstein MD, Coffelt SB, Duits DEM, van Miltenburg MH, Slagter M, de Rink I, et al. Loss of p53 triggers WNT-dependent systemic inflammation to drive breast cancer metastasis. Nature 2019;572(7770):538-42 doi 10.1038/s41586-019-1450-6

46. Ayturk UM, Jacobsen CM, Christodoulou DC, Gorham J, Seidman JG, Seidman CE, et al. An RNA-seq protocol to identify mRNA expression changes in mouse diaphyseal bone: applications in mice with bone property altering Lrp5 mutations. J Bone Miner Res 2013;28(10):2081-93. 
804 47. Tao L, van Bragt MP, Laudadio E, Li Z. Lineage tracing of mammary epithelial cells 805 using cell-type-specific cre-expressing adenoviruses. Stem Cell Reports 2014;2(6):770-9 806 doi 10.1016/j.stemcr.2014.04.004

807 48. Witcher PC, Miner SE, Horan DJ, Bullock WA, Lim KE, Kang KS, et al. Sclerostin 808 neutralization unleashes the osteoanabolic effects of Dkk1 inhibition. JCI Insight $809 \quad 2018 ; 3(11)$.

810

811

812 
Fig.1 | Wnt/FZD7 signaling is active in basal-like mammary tumors. (A) Representative immunostaining images detecting the levels of active $\beta$-catenin (non-phosphorylated form) in tumor tissues from p53/BRCA1-deficient, MMTV-PyMT and C3(1)-Tag breast cancer mouse models. DAPI staining marks the cell nucleus. Scale bar $=50 \mu \mathrm{m}$. (B) Quantitation of active $\beta$ catenin positive cells in (A). (C) Immunoblot analysis of active $\beta$-catenin expression in mammary tumors from models described in (A-B). Actin serves as a loading control. (D) 821 Quantitative real-time (qRT)-PCR analysis of expression of Fzd family genes in p53/BRCA1deficient (n=3), C3(1)-Tag $(\mathrm{n}=3)$ and MMTV-PyMT $(\mathrm{n}=2)$ tumors; error bars indicate mean \pm

823 SEM. (E) Upper panel: FACS analysis using a FZD7-specific antibody identified $~ 2.44 \%$ cells

824 as FZD7 $^{+}$in normal mammary epithelial cells (MECs). Lower panel: FZD7 ${ }^{+}$cells were isolated and subjected to further FACS analysis using antibodies against CD24 and CD29 to differentiate basal versus luminal EMCs, revealing that $\sim 81.3 \%$ of $\mathrm{FZD}^{+}$cells are basal EMCs. (F) The percentages of $\mathrm{FZD7}^{+}$cells in p53/BRCA1-deficient, C3(1)-Tag and MMTV-PyMT tumors, as well as in normal mouse mammary glands, were analyzed by FACS. The $\mathrm{FZD}^{+}$peaks are marked and compared in the upper panel and quantified in the lower panel (The $P$ values for p53/BRCA1-deficient, C3(1)-Tag and MMTV-PyMT models were <0.0001, 0.8556, 0.0178 respectively compared to normal mouse mammary glands). The representative FACS plots are shown in Supplementary Fig. 3.

Fig.2 | TcdB ${ }^{\text {FBD }}$ inhibits FZD1/2/7-mediated Wnt signaling. (A) Schematic diagrams showing the domain structures of TcdB, and the two short fragments derived from TcdB (TcdB ${ }^{\mathrm{FBD}}$ and $\mathrm{TcdB}^{\mathrm{mu}}$ ) used in this study. GTD: glucosyltransferase domain; CPD: cysteine protease domain; 837 Delivery/RBD: membrane translocation and receptor-binding domain; CROPs: combined repetitive oligopeptides domain. The structural model of $\mathrm{TcdB}^{\mathrm{FBD}}-\mathrm{CRD} 7$ complex shown is 839 modeled based on the crystal structure of TcdB ${ }^{\mathrm{FBD}}$-CRD2 (PDB code: 6C0B) and CRD7 (PDB 840 code:5T44). TcdB ${ }^{\mathrm{FBD}}, \mathrm{CRD} 2$, and CRD7 are colored pink, green, and blue, respectively. CRD:

841 cysteine-rich domain. (B) TcdB ${ }^{\mathrm{FBD}}$ blocked WNT3A-mediated signaling in MDA-MB-231 cells 842 in a dose-dependent manner, whereas $\operatorname{TcdB}^{\mathrm{mu}}$ showed no inhibition at nanomolar concentrations. 843 Wnt signaling activity was analyzed using the TOPFLASH/TK-Renilla (TK/RL) dual luciferase 
844 reporter assay (error bars indicate mean \pm SEM, three independent experiments). (C) Wnt 845 signaling activity in MDA-MB-231 cells was monitored using TK/RL assays over 5 days after 846 induction by WNT3A conditioned medium with the indicated concentrations of $\mathrm{TcdB}^{\mathrm{FBD}}$ or

$847 \mathrm{TcdB}^{\mathrm{mu}}$. Error bars indicate mean \pm s.e.m, three independent experiments. (D) Nude mice were 848 subcutaneously transplanted with TK/RL-transduced MDA-MB-231 cells and then treated at the 849 indicated time point with $\mathrm{TcdB}^{\mathrm{FBD}}$ or $\mathrm{TcdB}^{\mathrm{mu}}(20 \mathrm{mg} / \mathrm{kg}$ of body weight) by intraperitoneal (i.p.)

850 injection. D-Luciferin was injected $5 \mathrm{~min}$ before tumor tissues were isolated and the luciferase 851 activity in tumor tissues was then measured ex vivo and quantified (error bars indicate mean \pm 852 SEM, $\mathrm{n}=4-5$ tumors).

854 Fig.3 | TcdB ${ }^{\text {FBD }}$ inhibits growth of BL mammary tumors. (A) 2000 cells digested from the 855 indicated primary tumors were seeded in $20 \mu 1$ Matrigel in a 48 -well-plate. $\mathrm{TcdB}^{\mathrm{FBD}}$ or $\mathrm{TcdB}^{\mathrm{mu}}$ $856(150 \mathrm{nM})$ was added to the culture medium once per day. PBS was used as a vehicle control. 857 Representative images of tumor organoids at day 5 in culture are shown. Scale bar $=100 \mu \mathrm{m}$. (B) 858 Quantitation of organoids sizes at day 5 in culture for the indicated groups in (A). (C) 859 Quantitation of organoid numbers at day 5 in culture. (D) Mice were subcutaneously transplanted 860 with p53/BRCA1-deficient mammary tumor organoid cells (10,000 cells per mice) and treated 861 for the indicated period when tumor volumes reached $50 \mathrm{~mm}^{3}$ (left panel). The averaged tumor 862 volumes over time were measured and plotted (middle panel). Tumor tissues were harvested at 863 day 24 and weighted (right panel). Error bars represent SEM of 8-10 independently injected mice.

Fig.4 $\mid$ TcdB $^{\mathrm{FBD}}$ treatment in vivo does not affect the intestine and bones. (A) Six weeks old 866 female nude mice (Hsd: Athymic Nude-Foxn $1^{n u}$ ) were injected (i.p.) with the $\mathrm{TcdB}^{\mathrm{FBD}}(20,50$, 867 or $100 \mathrm{mg} / \mathrm{kg})$ or $\mathrm{TcdB}^{\mathrm{mu}}(20 \mathrm{mg} / \mathrm{kg})$ twice a week for five weeks. Their body weight gains were 868 monitored and plotted. Error bars indicate mean \pm SEM, $n=8-10$ mice. (B) Mice were treated 869 with $\mathrm{TcdB}^{\mathrm{FBD}}$ as described in panel A. EdU was injected (i.p., $100 \mathrm{mg} / \mathrm{kg}$ ) $12 \mathrm{~h}$ before 870 euthanization. Intestine tissues were harvested, fixed, and analyzed. The representative images 871 were shown in the left panel and quantification of the percentage of EdU-positive cells per crypt 872 was plotted in the right panel. Scale bar $=200 \mu \mathrm{m} . P=0.28$. (C) Mice were treated with $\mathrm{TcdB}^{\mathrm{FBD}}$ 873 as described in panel $\mathrm{A}$ and their right femur bones were extracted, fixed, and subjected to 874 micro-computed tomography $(\mu \mathrm{CT})$ analysis. Representative $\mu \mathrm{CT}$ reconstructions of the 
875 midshaft femur cortical bone (upper row), distal femur metaphyseal bone (middle row), and 876 entire distal femur with the ventral half of the femur digitally removed to reveal the cancellous 877 compartment (lower row) are shown. $\mathrm{N}=6$ /dose group. (D) Quantification of the $\mu \mathrm{CT}$ analysis 878 described in panel $\mathrm{C}$ for trabecular bone volume fraction (BV/TV), trabecular number (Tb.N), 879 trabecular thickness (Tb.Th), and cortical area (Ct.Ar), $P=0.67,0.63$. $0.68,0.67$, respectively.

Fig.5 | TcdB ${ }^{\mathrm{FBD}}$ inhibits tumorigenic potential of BL mammary tumor cells. (A) Cells dissociated from p53/BRCA1-deficient mammary tumor tissues were resuspended and plated into round-bottom 96-well ultralow attachment plates in the sphere culture medium containing with $150 \mathrm{nM} \mathrm{TcdB}{ }^{\mathrm{FBD}}$, $\mathrm{TcdB}^{\mathrm{mu}}$, or PBS (control). Representative images of tumorspheres formed at day 5 and day 15 in culture are shown. Scale bar $=200 \mu \mathrm{m}$. (B) The percent of tumorspheres were quantified following three passages of p53/BRCA1-deficient mammary tumor cells $(5,000$ cells/well for primary culture, and 2,000 cells/well for secondary and tertiary culture) with $150 \mathrm{nM} \mathrm{TcdB}{ }^{\mathrm{FBD}}$ or $\mathrm{TcdB}^{\mathrm{mu}}$ or PBS in the sphere culture medium. (C) Analysis of the sphere-forming capabilities of p53/BRCA1-deficient mammary tumor cells using the limiting dilution assay. Cells were seeded in the presence of $150 \mathrm{nM} \mathrm{TcdB}{ }^{\mathrm{FBD}}$ or $\mathrm{TcdB}^{\mathrm{mu}}$ or PBS vehicle. Sphere formation was counted 10-15 days post-seeding. The frequency of sphere-forming cells

893 (http://bioinf.wehi.edu.au/software/elda/index.html): Control = 1/239 (lower 449, upper 128); $894 \operatorname{TcdB}^{\mathrm{FBD}}=1 / 895$ (lower 1,594, upper 502), $P=0.00192$, compared with control, $\mathrm{TcdB}^{\mathrm{mu}}=1 /$ 895318 (lower 579, upper 175). (D) Tumor organoid cells (10, 100, or 1000 cells) derived from p53/BRCA1-deficient tumors were injected subcutaneously into nude mice. The growth of tumor was evaluated daily for 3-month. Once one tumor grows out in each group (10, 100, or 1000 cells), the mice was divided into three groups, received one of the following treatments twice a week: PBS (150 $\mu \mathrm{L} /$ mice), endo-toxin free $\operatorname{TcdB}^{\mathrm{FBD}}(20 \mathrm{mg} / \mathrm{kg})$, or TcdB ${ }^{\mathrm{mu}}(20 \mathrm{mg} / \mathrm{kg})$. Values in brackets indicate the number of organoid cells, the number of tumors obtained versus the total injected mice number. (E) Analysis of the tumorigenesis of p53/BRCA1-deficient mammary tumor organoid cells using the limiting dilution assay as described in (D). Frequency of TICs: Control = 1/62 (lower 134, upper 28.8); $\mathrm{TcdB}^{\mathrm{FBD}}=1 / 289.9($ lower 701, upper 120.1) $P=0.0013$, compared with control, $\mathrm{TcdB}^{\mathrm{mu}}=1 / 73.1$ (lower 160, upper 33.4). (F) Tumor latency plotted as percentage of tumor-free mice implanted with 100 p53/BRCA1-deficient mammary tumor 
906 organoid cells following the indicated treatment. (G) Kaplan-Meier survival curves of nude mice

907 bearing xenograft tumors treated as indicated.

908

909 Fig. $6 \mid$ TedB $^{\text {FBD }}$ inhibits cisplatin-resistant mammary tumor cells. (A-B) Tumor organoid 910 cells from p53/BRAC1-deficient tumor model (A) or C3(1)-Tag model (B) were injected into

911 nude mice, and mice were then treated with $\mathrm{TcdB}^{\mathrm{FBD}}$ alone, cisplatin alone, or a combination of

912 both $\mathrm{TcdB}^{\mathrm{FBD}}$ and cisplatin as indicated. Tumor volume were recorded and plotted over time.

913 Error bars indicate mean \pm SEM, $n=8$ mice. (C) FACS analysis of FZD7 ${ }^{+}$cells in the indicated 914 tumors from p53/BRCA1-deficient $(\mathrm{n}=5)$ and C3(1)-Tag $(\mathrm{n}=4)$ models. Error bars indicate mean $915 \pm$ SEM. (D) Tumor organoid cells from MMTV-PyMT model were injected into nude mice, and 916 mice were then treated with $\mathrm{TcdB}^{\mathrm{FBD}}$ alone, cisplatin alone, or a combination of both $\mathrm{TcdB}^{\mathrm{FBD}}$ 917 and cisplatin as indicated. Tumor volume were recorded and plotted over time. Error bars 918 indicate mean \pm SEM, $\mathrm{n}=6-8$ mice. (E) Representative images of MMTV-PyMT mammary 919 tumor organoids treated with $\mathrm{TcdB}^{\mathrm{FBD}}$ alone $(150 \mathrm{nM})$, cisplatin alone $(0.2 \mu \mathrm{M})$, or a 920 combination of cisplatin and $\mathrm{TcdB}^{\mathrm{FBD}}$. Scale bar $=100 \mu \mathrm{m}$. (F) Quantitation of organoid sizes 921 for indicated groups described in (E). (G) Quantitation of organoid numbers for indicated groups 922 described in (E). (H) qRT-PCR analysis of EMT-related genes (Vim, Zeb1, Tcf4) and Fzd7 genes 923 in tumor cells from $M M T V-P y M T$ model after treatment with $\operatorname{TcdB}^{\mathrm{FBD}}$, cisplatin, or a 924 combination of both $(P<0.01)$.

925 
Supplementary Figure Legends:

929 levels of FZDs in different subtypes of human breast cancer based on bc-GenExMiner online 930 tool.

Supplementary Fig. S2 | Expression levels of FZDs in murine breast cancer models. High 933 expression levels of $F z d 7$ and $F z d 6$ in mouse models for human BLBC/TNBC; data was based 934 on GEO accession \# GSE25488 (in heatmap, red to blue represents highest to lowest expression 935 levels). The first five from the left side (marked as mammary tumor tissue rep1-5) represent the 936 C3(1)-Tag model. models. (A) Schematic diagram showing the generation of a p53/BRAC1-deficient breast cancer model by intraductal injection of $\mathrm{Ad}-\mathrm{K} 8$-Cre into $\operatorname{Trp} 53^{L / L} ; \mathrm{Brcal}^{L / L} ; R 26 \mathrm{Y}$ female mice. (B) 941 Kaplan-Meier tumor-free results showing that $\operatorname{Trp5} 3^{L / L} ; B r c a 1^{L / L} ; R 26 Y$ female mice $(\mathrm{n}=17)$ 942 injected with $\mathrm{Ad}$-K8-Cre developed malignant mammary tumors over time after Ad-K8-Cre 943 injection. (C) Representative FACS plots of $\mathrm{FZD}^{+}$cells from normal mammary glands, p53/BRCA1-deficient, MMTV-PyMT, and C3(1)-Tag tumors.

Supplementary Fig. S4 | TcdB ${ }^{\mathrm{FBD}}$ inhibits Wnt signaling in human breast cancer cell lines.

947 (A) Left panel: Phylogenetic analysis of human FZD proteins (15); Right panel: qRT-PCR 948 analysis of $F z d s$ in MDA-MB-231 cells. (B) Cell viability measured by the MTT assay showed 949 that $\mathrm{TcdB}^{\mathrm{FBD}}$ did not exhibit cytotoxicity to the indicated human cell lines (error bars indicate 950 mean \pm SEM, three independent experiments). (C) Representative images of clonogenic growth 951 of PaTu8988s and HPAF-II cells cultured in the presence of $\mathrm{TcdB}^{\mathrm{FBD}}(150 \mathrm{nM})$ or LGK974 (100 $952 \mathrm{nM}$ ). (D) Representative images of sphere formation assay in PaTu8988s and HPAF-II cells 953 cultured in the presence of $\operatorname{TcdB}^{\mathrm{FBD}}(150 \mathrm{nM})$ or LGK974 (100 nM). (E) Quantitation of colony 954 numbers and sphere formation from (C-D), error bars indicate mean \pm SEM, $n=4$. 
957 mammary tumor cells. (A) Experiments were carried out as described in Fig. 3A. qRT-PCR 958 analysis showing downregulation of Wnt signaling-related genes (Axin2 and Rnf43) and EMT959 associated genes (Vim and Zeb1) in tumor organoids upon $\mathrm{TcdB}^{\mathrm{FBD}}$ treatment. (B) Experiments 960 were carried out as described in Fig. 3D. qRT-PCR analysis showing downregulation of Wnt961 associated genes (Axin2 and Rnf43) and EMT-associated genes (Vim and Zeb1) in TcdB ${ }^{\mathrm{FBD}}$ 962 treated xenograft tumors. (C) Experiments were carried out as described in Fig. 3D. 963 Representative immunostaining images of LEF1 expression (green) in different treatment groups are shown (Control, $\mathrm{TcdB}^{\mathrm{FBD}}$ or $\left.\mathrm{TcdB}^{\mathrm{mu}}\right)$. Scale bar $=50 \mu \mathrm{m}$.

Supplementary Fig. S6 $\mid$ TcdB $^{\mathrm{FBD}}$ inhibits growth of human TNBC organoids. The viability of two lines of human breast cancer organoids, a luminal tumor line 74T (panel A) and a BL tumor line $86 \mathrm{~T}$ (panel B), were exposed to the indicated concentrations of $\mathrm{TcdB}^{\mathrm{FBD}}$ or $\mathrm{TcdB}^{\mathrm{mu}}$. FZD7 $^{+}$. (A) FACS analysis using FITC-TcdB ${ }^{\mathrm{FBD}}$ and anti-FZD7 antibody showed that primary p53/BRCA1-deficient tumors cells targeted by $\mathrm{TcdB}^{\mathrm{FBD}}$ are largely FZD7 ${ }^{+}$. (B) Representative images showing the tumorspheres formed from p53/BRCA1-deficient tumor cells. (C)

975 Tumorsphere cells cultured from p53/BRCA1-deficient tumors were examined by FACS 976 analysis using an anti-FZD7 antibody. (D) Representative images showing the tumor organoid 977 formed from p53/BRCA1-deficient tumor cells. (E) FACS analysis of FZD7 ${ }^{+}$cells in the tumor 978 organoids described in (D) showing that most organoid cells express FZD7.

Supplementary Fig. S8 $\mid$ TcdB $^{\mathrm{FBD}}$ and cisplatin showed synergistic effect in inhibiting BL mammary tumor organoids. (A) Representative images of p53/BRCA1-deficient mouse 982 mammary tumor organoids treated with $\mathrm{TcdB}^{\mathrm{FBD}}$ alone $(150 \mathrm{nM})$, cisplatin alone $(0.2 \mu \mathrm{M})$, or a 983 combination of both. (B) Quantitation of organoids sizes for the indicated treatment groups in 984 (A). (C) Quantitation of organoid numbers for the indicated groups in (A). (D) Representative 985 pictures of C3(1)-Tag mouse mammary tumor organoids treated with $\mathrm{TcdB}^{\mathrm{FBD}}$ alone, cisplatin 986 alone, or a combination of both. (E) Quantitation of organoids sizes for the indicated treatment 
987 groups in (D). (F) Quantitation of organoid numbers for the indicated groups in (D). Scale bar = $988100 \mu \mathrm{m}$. 
Figure 1
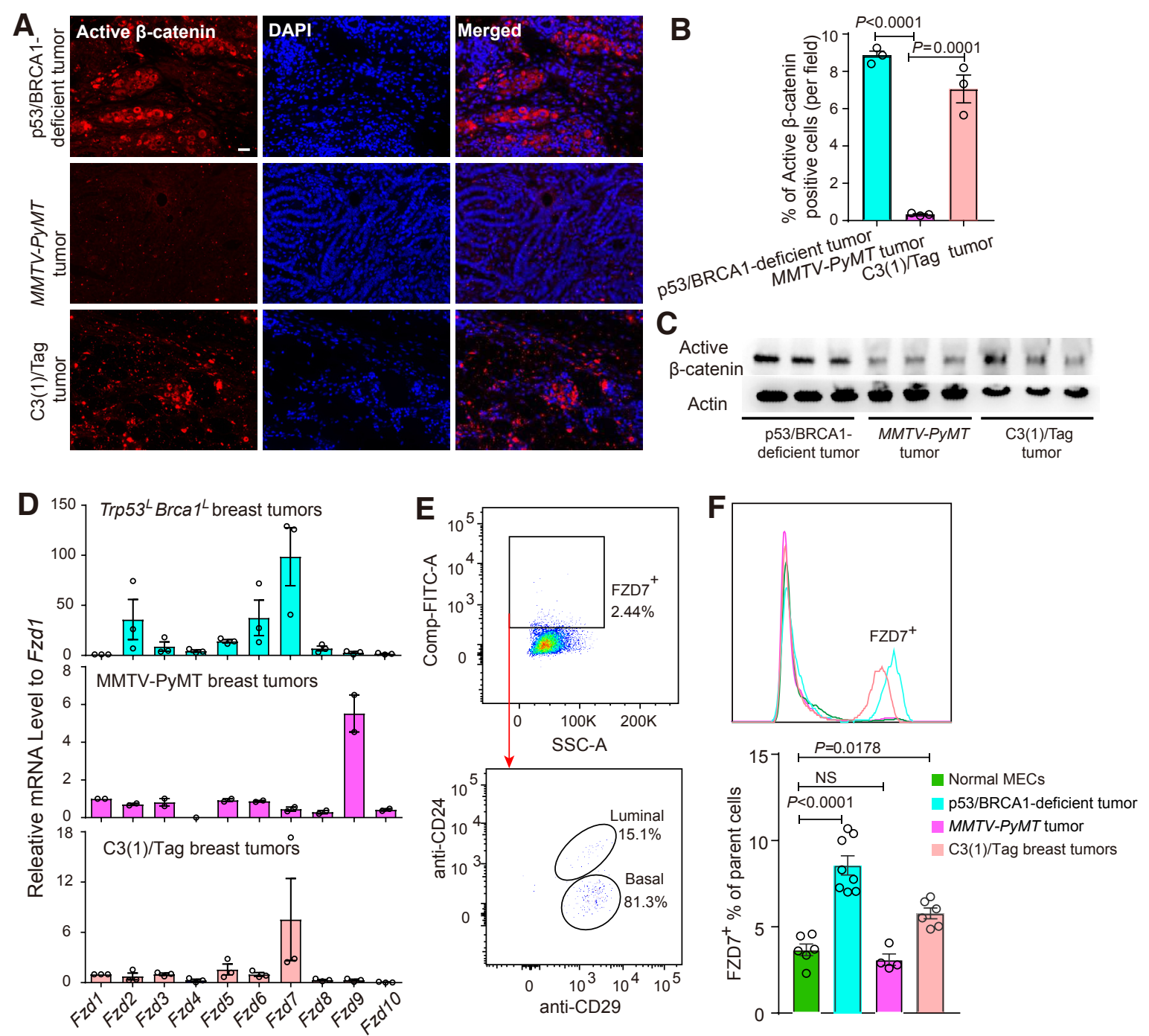
Figure 2
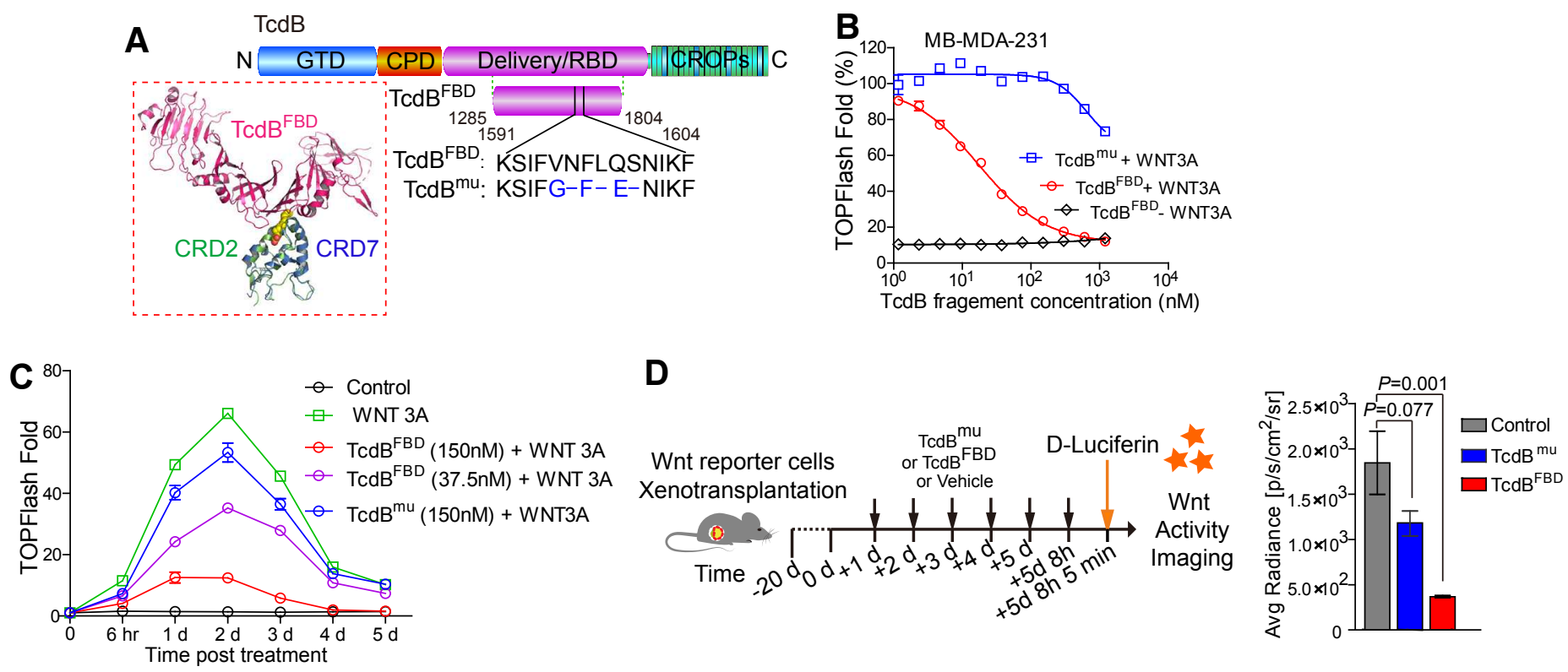


\section{Figure 3}
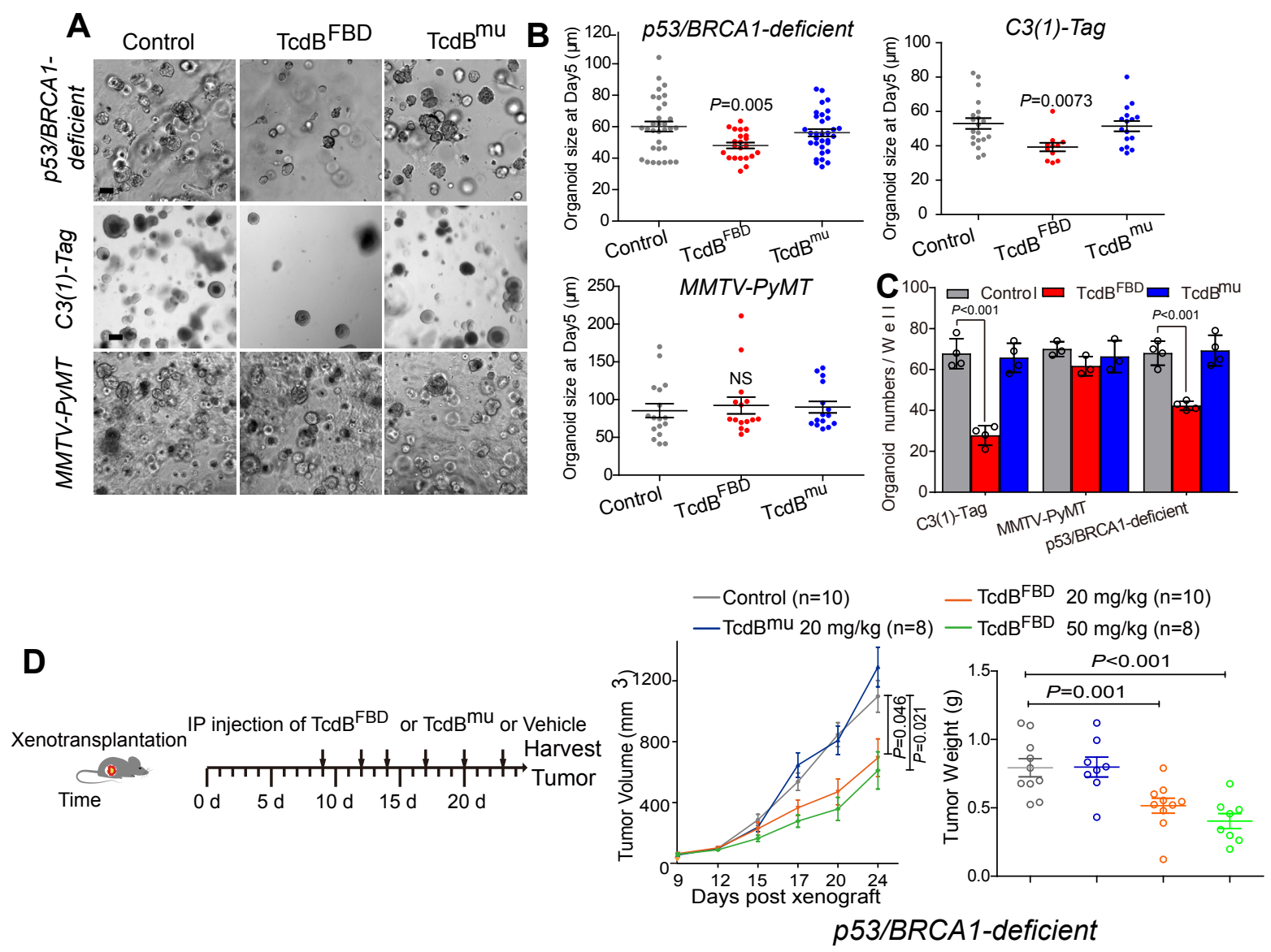


\section{Figure 4}
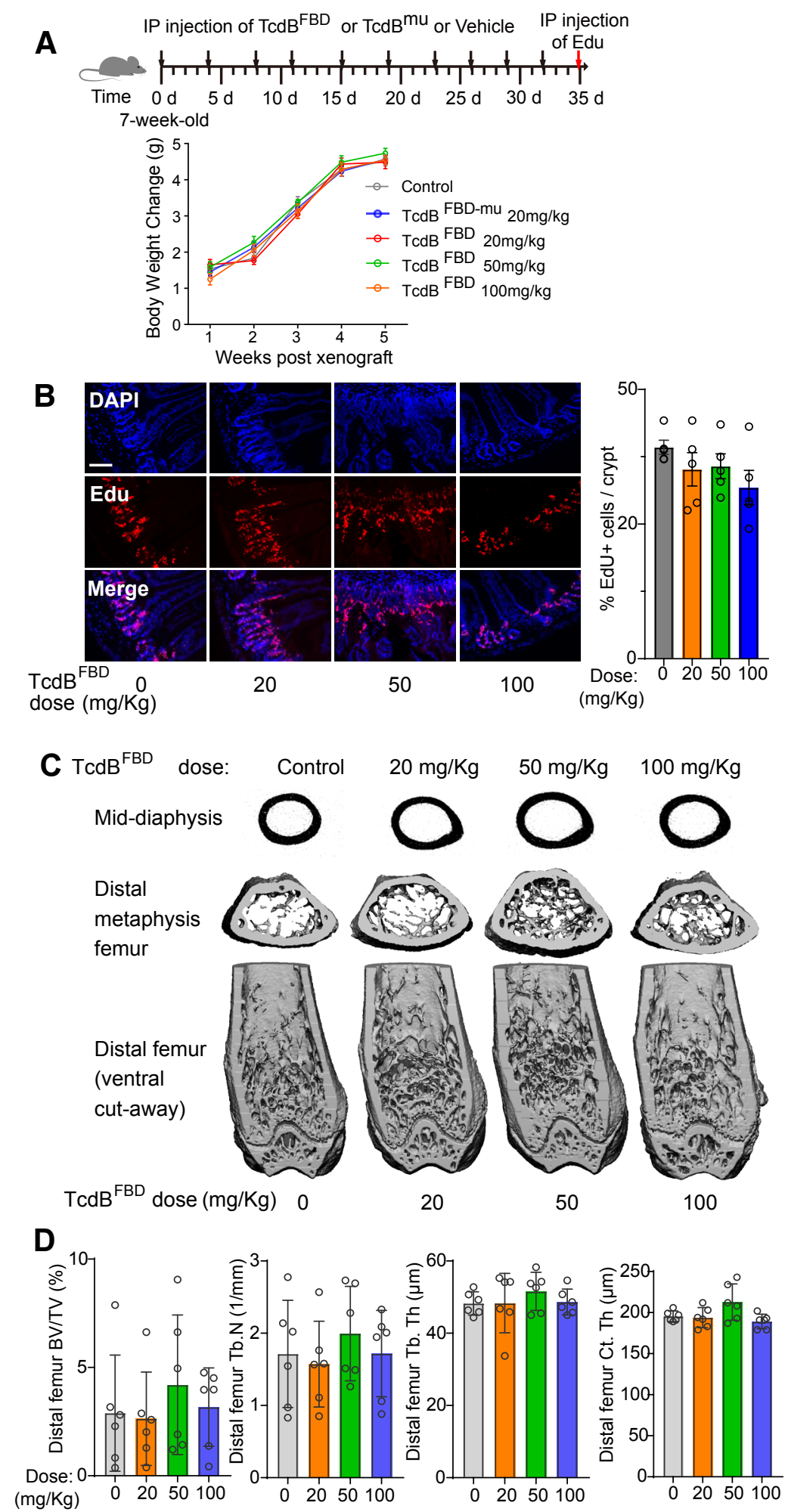


\section{Figure 5}
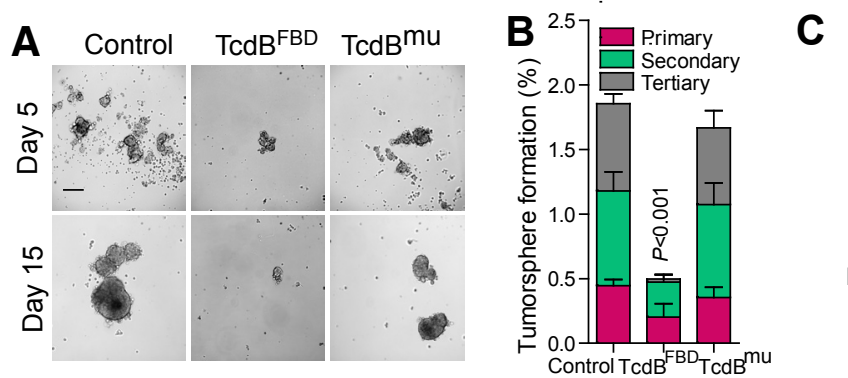

\begin{tabular}{cccc}
\hline Number of cells & Control & $\mathrm{TcdB}^{\mathrm{FBD}}$ & $\mathrm{TcdB}^{\mathrm{mu}}$ \\
\cline { 2 - 4 } & \multicolumn{3}{c}{ Tumor sphere incidence } \\
\hline 2000 & $6 / 6$ & $6 / 6$ & $6 / 6$ \\
1000 & $6 / 6$ & $4 / 6$ & $6 / 6$ \\
500 & $6 / 8$ & $3 / 8$ & $5 / 8$ \\
100 & $3 / 8$ & $0 / 8$ & $3 / 8$ \\
10 & $2 / 8$ & $0 / 8$ & $1 / 8$ \\
\hline Repopulating frequency & $1 / 239$ & $1 / 895$ & $1 / 318$ \\
$95 \% \mathrm{Cl}$ & $1 /(449-128)$ & $1 /(1594-502)$ & $1 /(579-175)$ \\
$P$ & - & 0.00192 & 0.5 \\
\hline
\end{tabular}

$D_{1500 \text { - Control }(1000 ; 6 / 6)}$ - $\operatorname{TcdB}^{\mathrm{mu}}(1000 ; 6 / 6)$

Xenotransplantation IP injection of $\mathrm{TcdB}^{\mathrm{FBD}}$

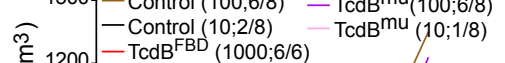
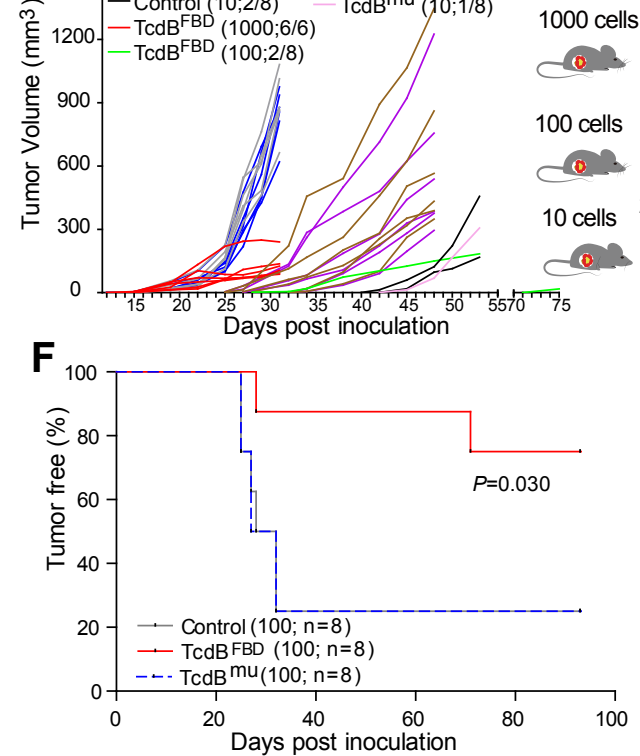

E

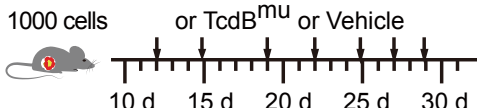

\begin{tabular}{cccc}
\hline \multirow{2}{*}{ Number of cells } & Control & TcdBFBD & TcdB \\
\cline { 2 - 4 } & \multicolumn{3}{c}{ Take rate } \\
\hline 1000 & $6 / 6$ & $6 / 6$ & $6 / 6$ \\
100 & $6 / 8$ & $2 / 8$ & $6 / 8$ \\
10 & $2 / 8$ & $0 / 8$ & $1 / 8$ \\
\hline Repopulating frequency & $1 / 62$ & $1 / 289.9$ & $1 / 73.1$ \\
$95 \%$ Cl & $1 /(134-28.8)$ & $1 /(701-120.1)$ & $1 /(160-33.4)$ \\
$P$ & - & 0.013 & 0.765 \\
\hline \multicolumn{4}{c}{}
\end{tabular}

G

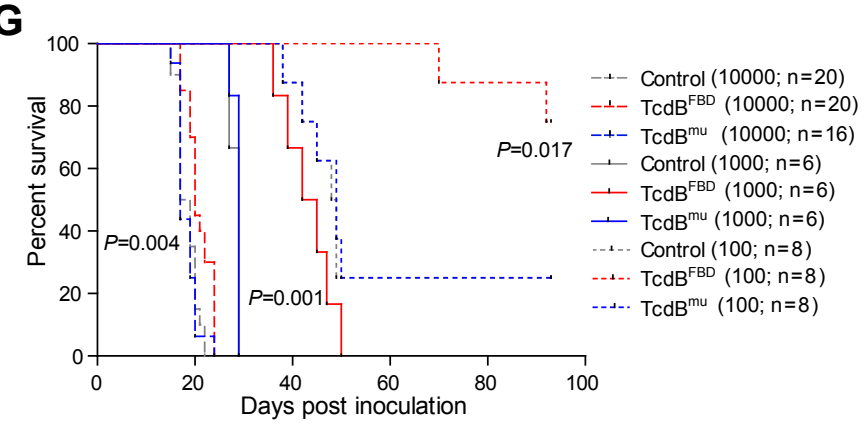


Figure 6

A

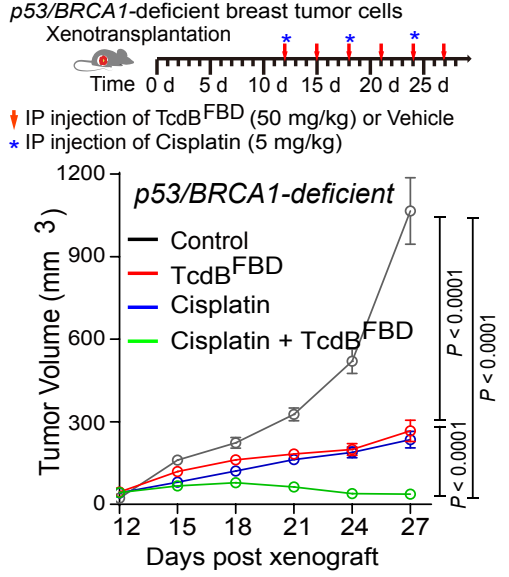

B C3(1)-Tag breast tumor cells

Xenotransplantation * c)

Time $0 \mathrm{~d} 15 \mathrm{~d} 20 \mathrm{~d} 25 \mathrm{~d} 30 \mathrm{~d} 35 \mathrm{~d} 40 \mathrm{~d}$ - IP injection of TcdBFBD $(50 \mathrm{mg} / \mathrm{kg})$ or Vehicle * IP injection of Cisplatin $(5 \mathrm{mg} / \mathrm{kg})$

$$
\begin{aligned}
& - \text { Control } \\
& - \text { Cisplatin } \\
& - \text { TcdB FBD } \\
& - \text { Cisplatin + TcdB FBD }
\end{aligned}
$$
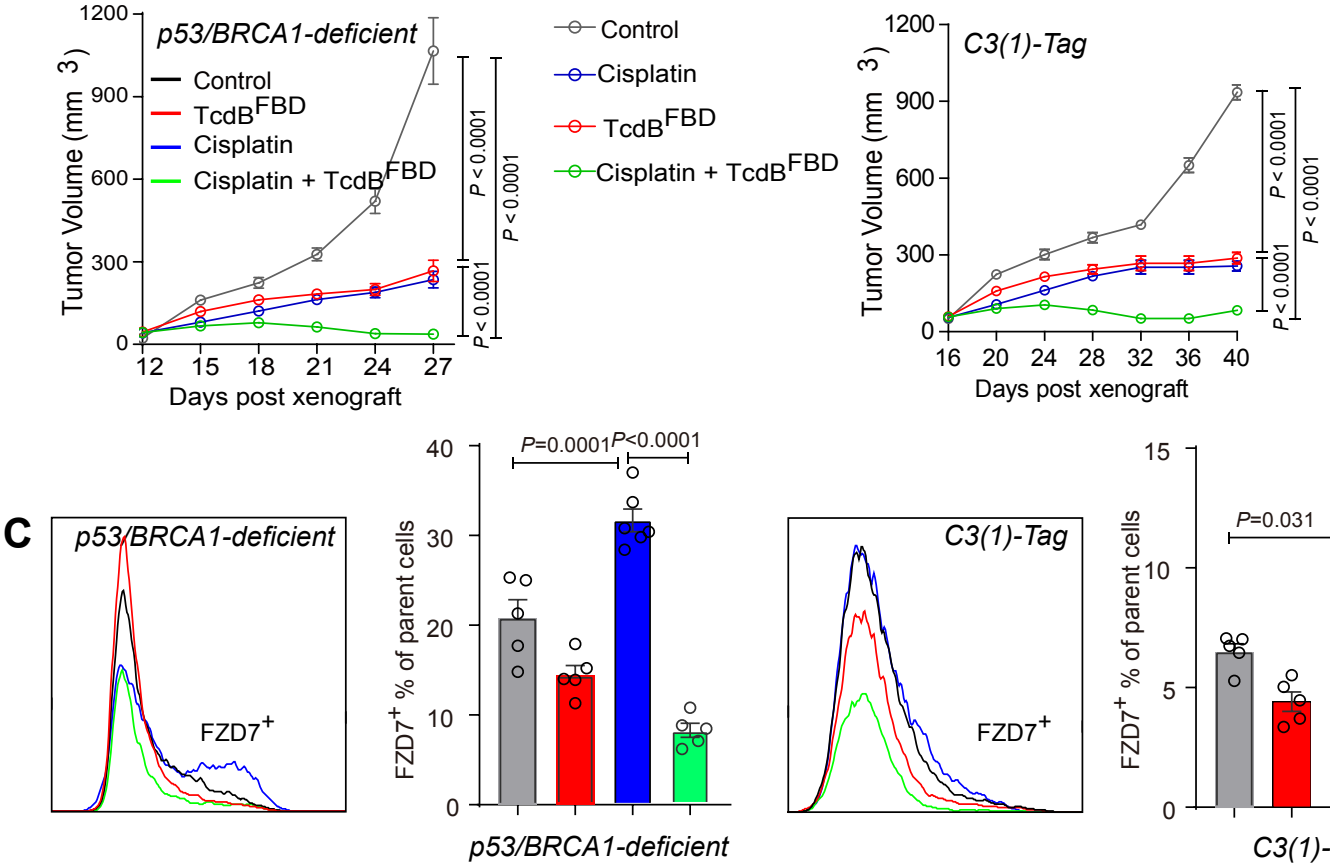
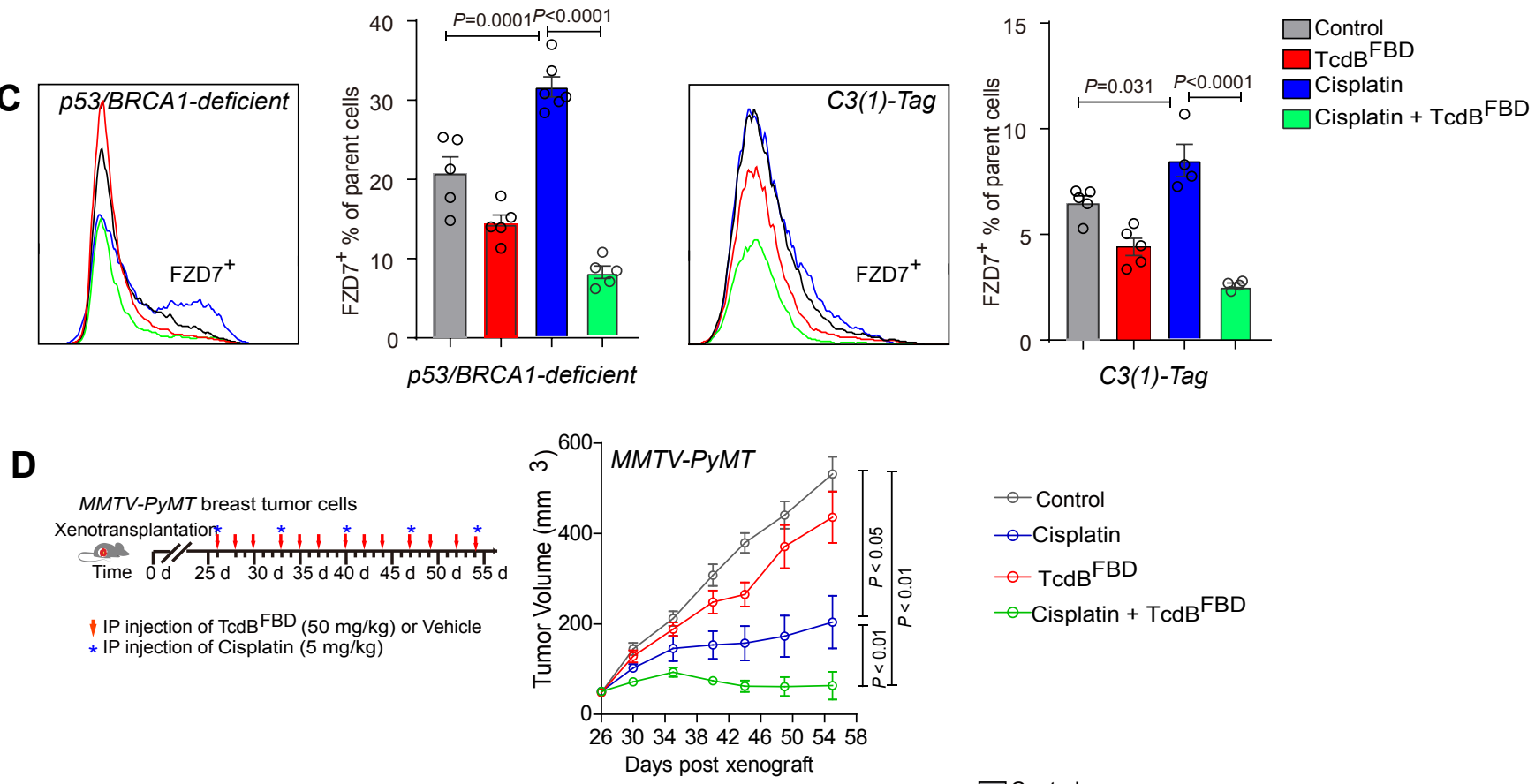

$$
\begin{aligned}
& - \text { Control } \\
& - \text { Cisplatin } \\
& - \text { TcdB FBD } \\
& - \text { Cisplatin + TcdB FBD }
\end{aligned}
$$

* IP injection of Cisplatin ( $5 \mathrm{mg} / \mathrm{kg}$ )
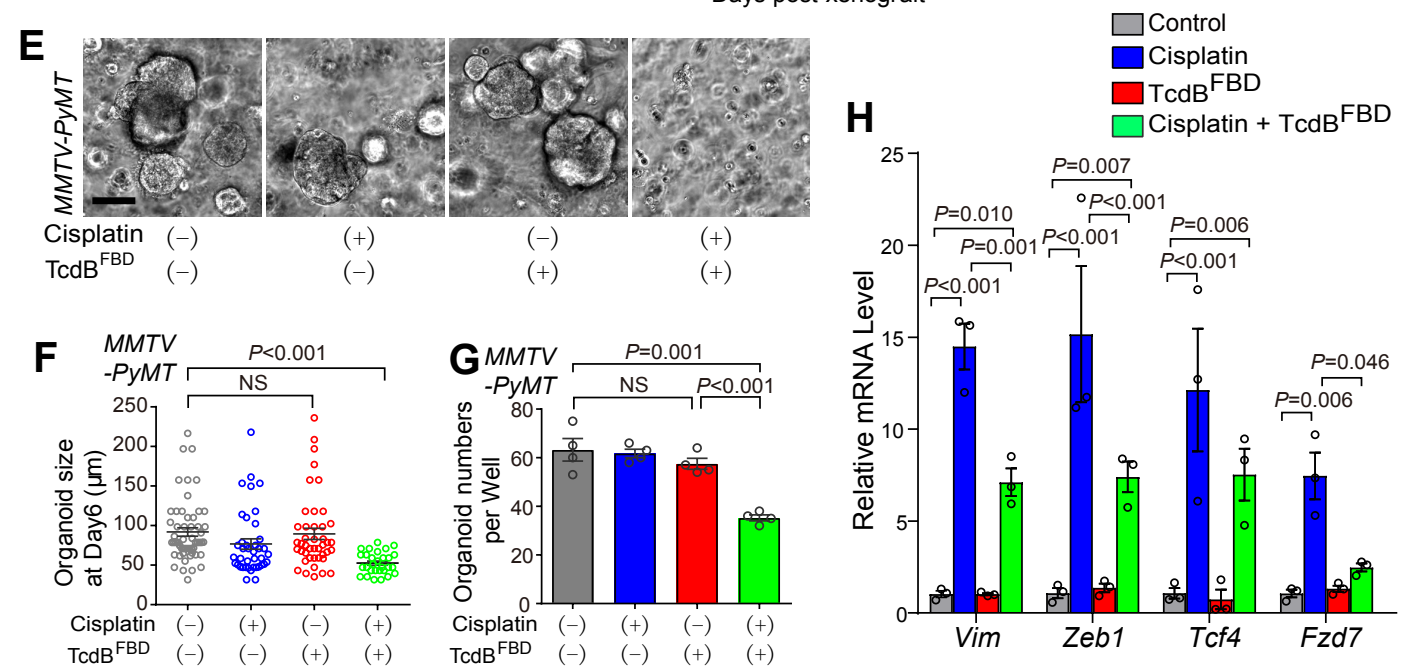


\section{Supplementary Fig. \$1}

Box plot of FZD1 expression according to

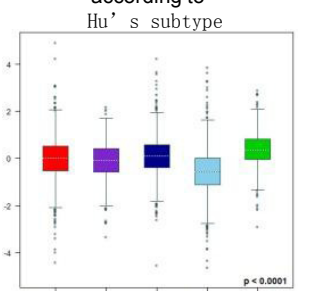

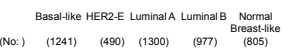

Box plot of FZD3 expression according to

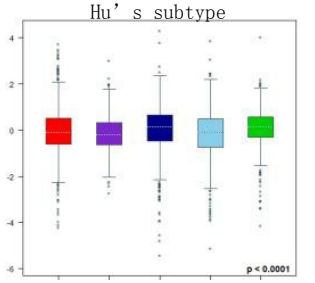

Basaltike HER2-E LuminalA Luminal B Normal

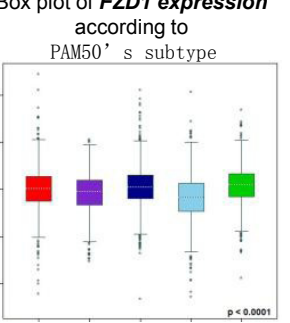

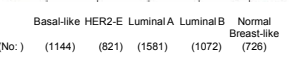

Box plot of FZD3 expression according to

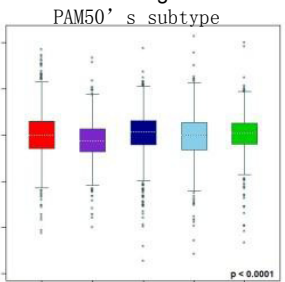

Basal-1ike HER2-E LuminalA LuminalB B Nomal

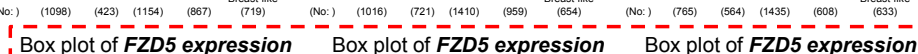

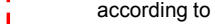

Hu' s subtype

$$
\text { according to }
$$

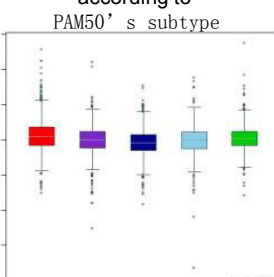

Basal-like HER2-E LuminalA Luminal B Normal Basat-IKe HER2-E LuminalA LuminalB Normal

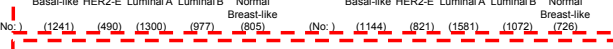
Box plot of FZD7 expression according to
Hu's subtype

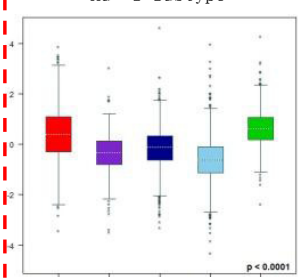

Basal-1ike HER2-E LuminalA LuminalB B Nomal

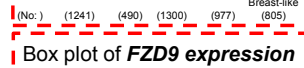

I Hu's subtype

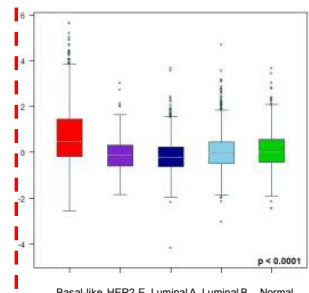

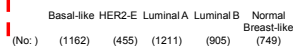

Basal-ike HER2-E L Luminal A Luminal B Normal
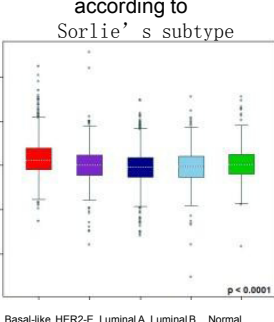

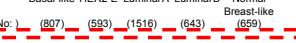
Box plot of FZD7 expression Box plot of FZD7 expression according to

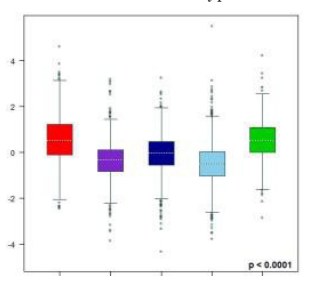

Basalt-1ike HER2-E Luminal A Luminal B Normal

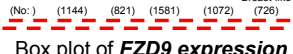
according to PAM50's subtype

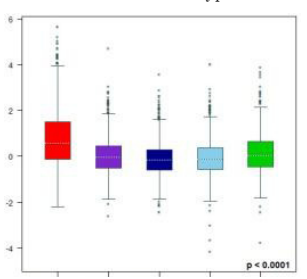

Basal-Hike HER2.E LuminalA L LuminalB Norrat
Box plot of FZD1 expression according to

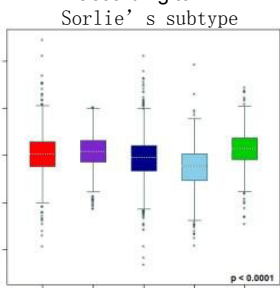

$\begin{array}{lll}\text { Basal-ike HER2.E Luminal A LuminalB } & \text { Nomal } \\ \text { Breastl-lek } \\ \text { (659) }\end{array}$

Box plot of FZD3 expression according to

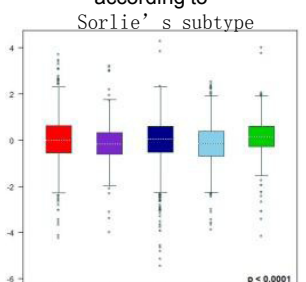

Box plot of FZD2 expression

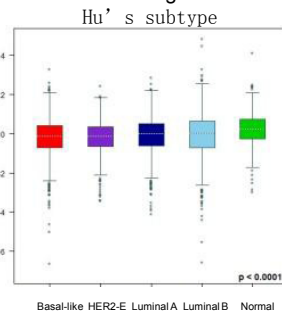

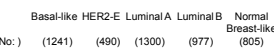

Box plot of FZD4 expression

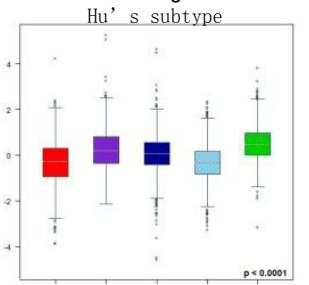

Basal-1ike HER2-E LUminalA LuminalB Normal

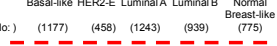

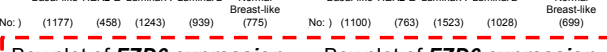
Box plot of FZD 6 expression

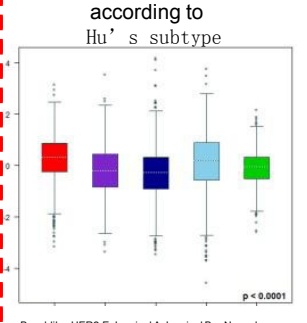
PAM50' s subtype

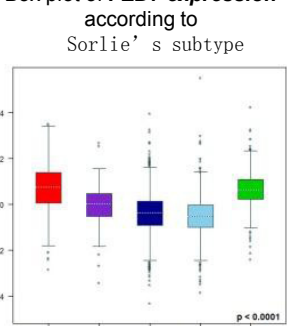

Basal-like HER2-E LuminalA LuminalB Normal

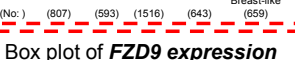
according to

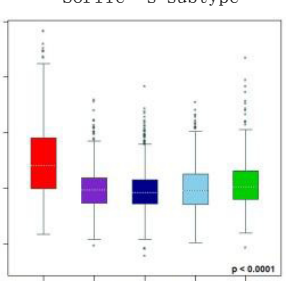
Sorlie's subtype
Basal-1ike HER2-E LuminalA LuminalB Normal

$1-1268)$
Box plot of FZD8 expression

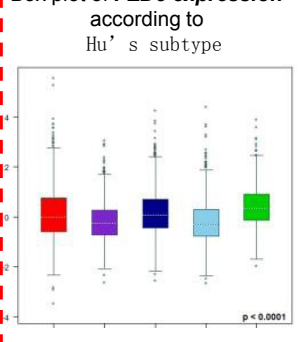

Basal-Hke HER2-E LuminalA LuminalB B Normal
Breastlke
(775) (1177)
Box plot of FZD10 expression according to

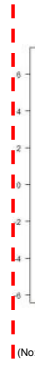
according to according to

Hu' s subtype
Box plot of FZD2 expression according to

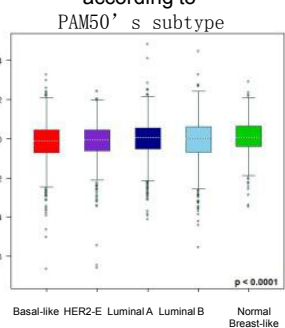

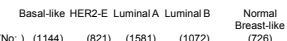

Box plot of FZD4 expression according to

PAM50's subtype

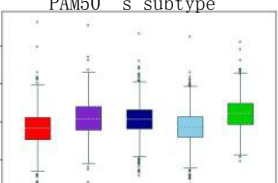

Box plot of FZD2 expression according to

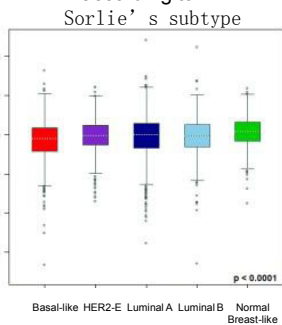

Basal-like HER2-E LuminalA LuminalB Normal
(No:)
(807)

Box plot of FZD4 expression according to

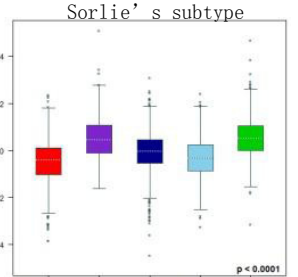

Basal-1ike HER2-E LuminalA Luminali B Nomal

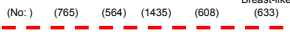
Box plot of $\overline{F Z} \bar{D} 6$ expression according to

$$
\text { according to }
$$

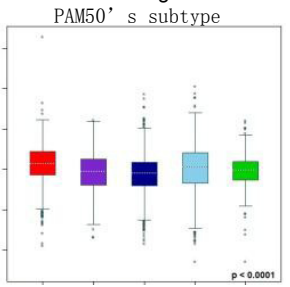

asal-1ike HER2-E Luminal A Luminal B Normal

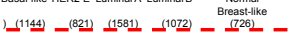

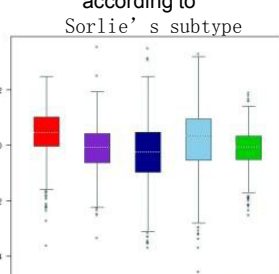

Basal-Iike HER2-E LuminalA Luminal B Normal $-{ }^{-107)}-{ }^{(593)}-{ }^{(1516)}-{ }^{(643)}--^{(659)}-$ according to PAM50's subtype
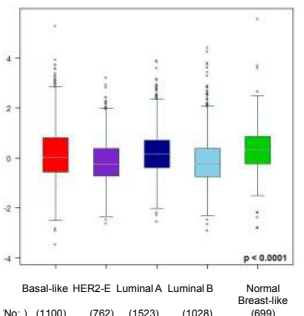

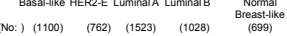
Box plot of FZD10 expression according to PAM50' s subtype

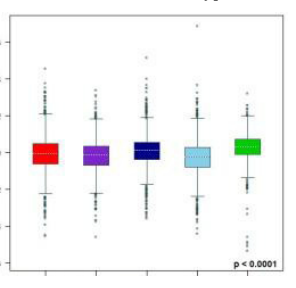

p<c.00001

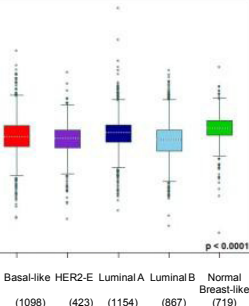

Box plot of FZD8 expression according to

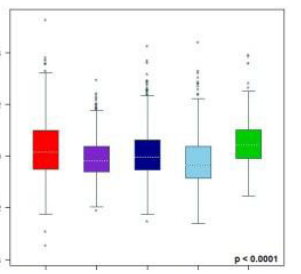

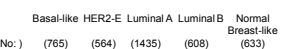

Box plot of FZD10 expression according to

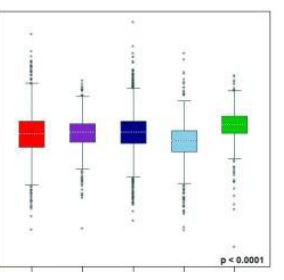

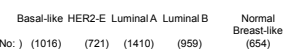

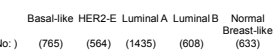




\section{Supplementary Fig. S2}

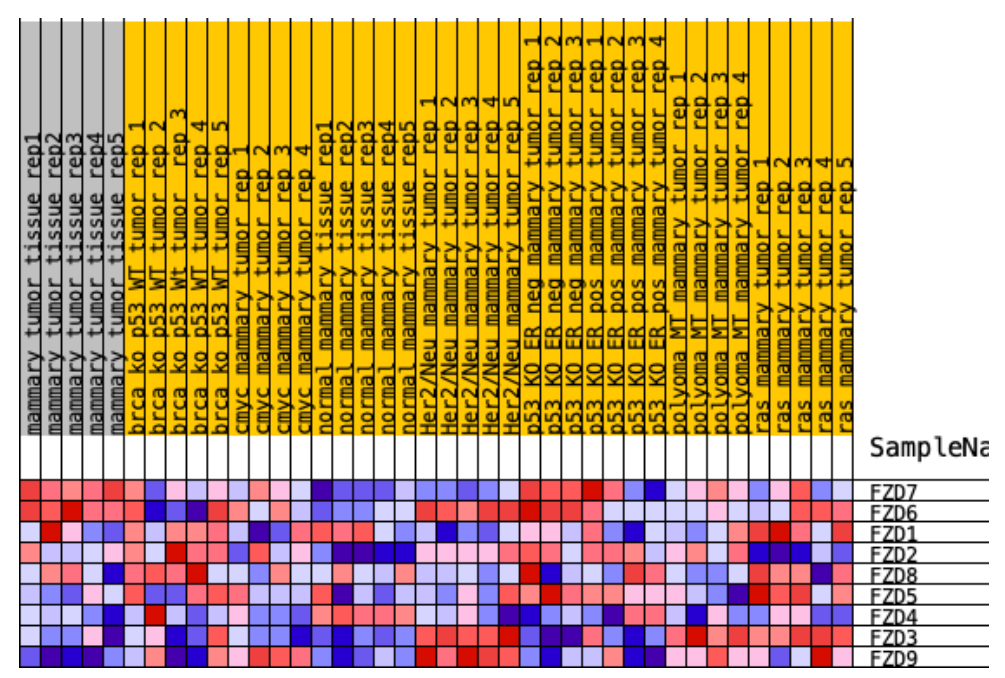


Supplementary Fig. S3
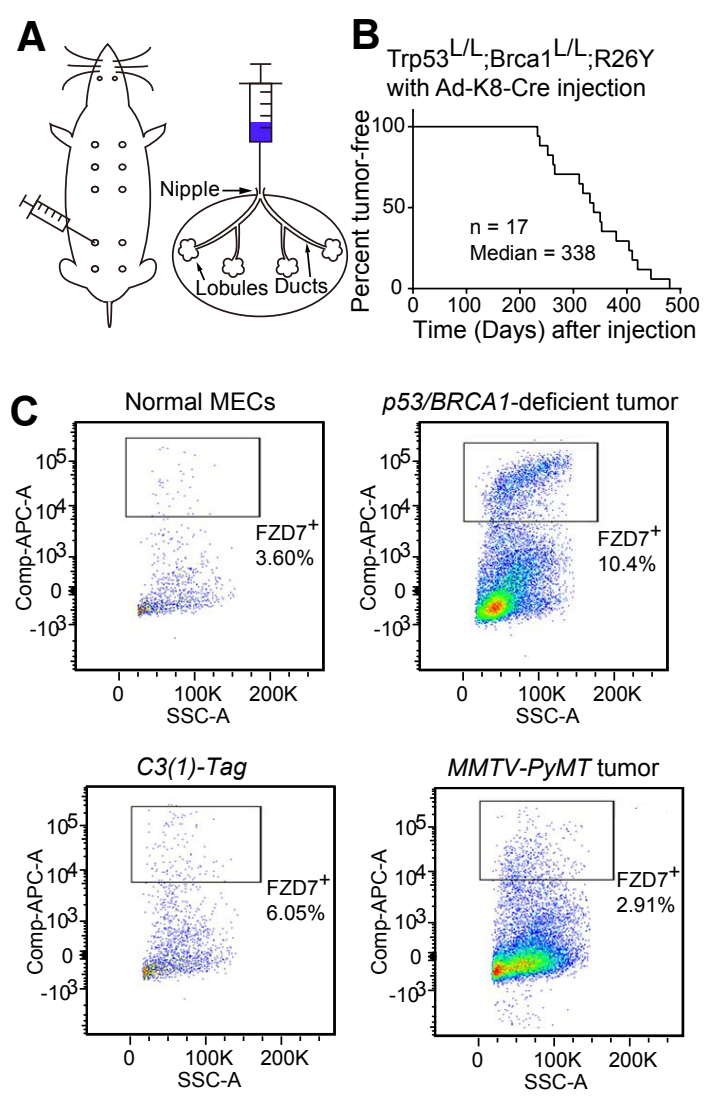


\section{Supplementary Fig. S4}

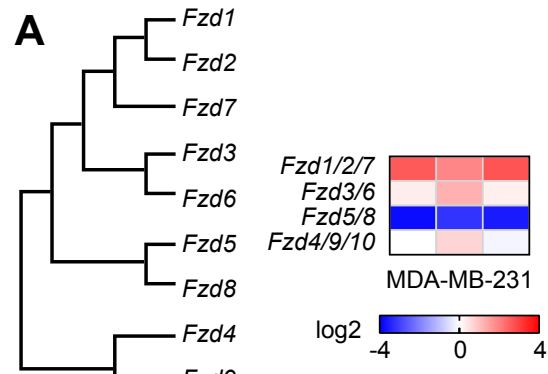

B
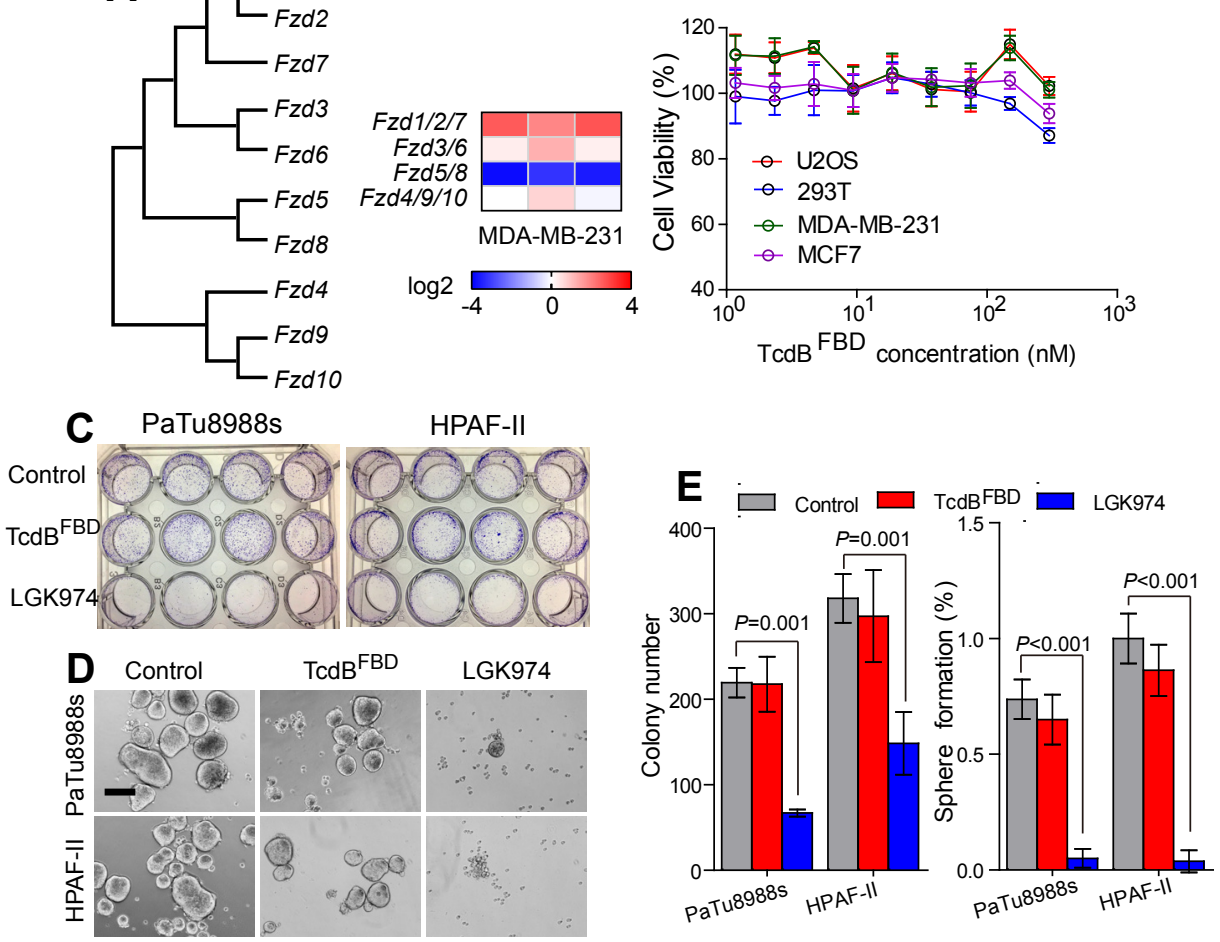


\section{Supplementary Fig. S5}

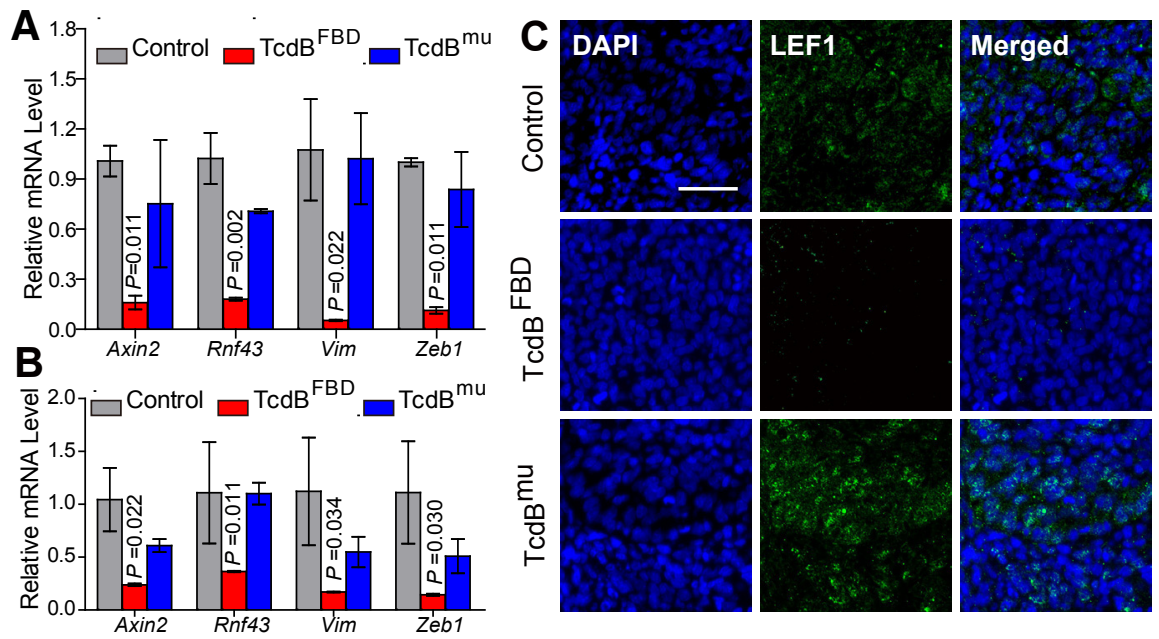


Supplementary Fig. S6

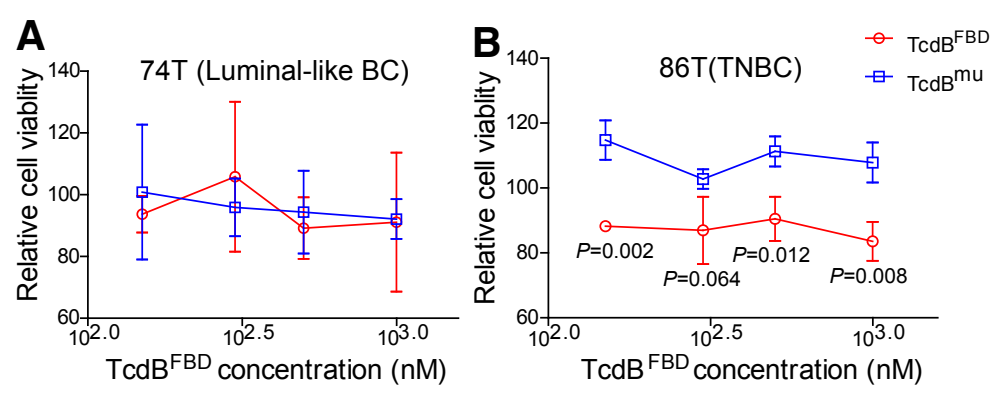




\section{Supplementary Fig. \$7}
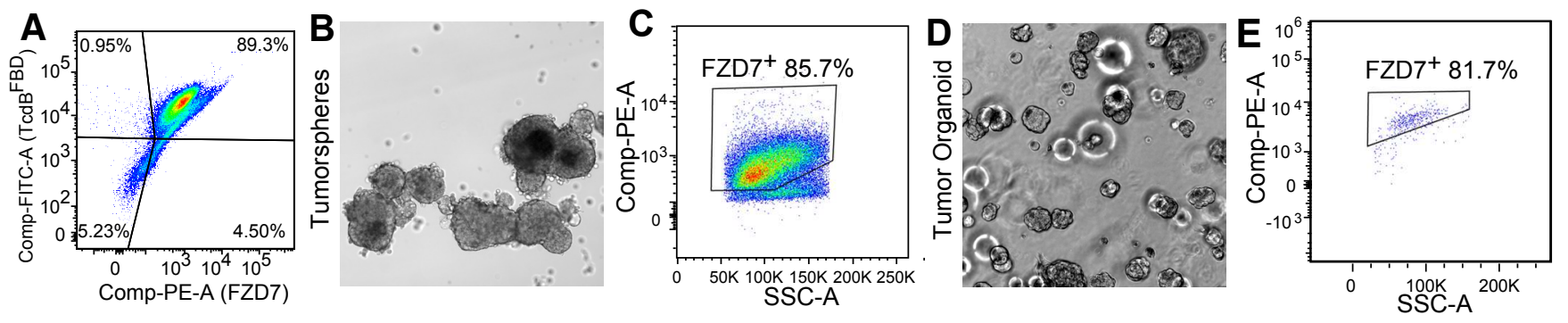
Supplementary Fig. S8

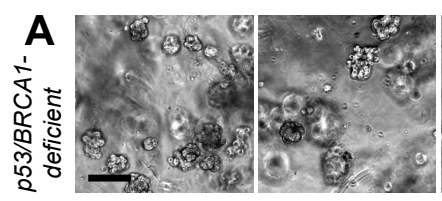

Cisplatin (-)

$\mathrm{TcdB}^{\mathrm{FBD}} \quad(-)$

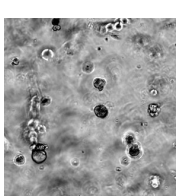

(+)

(-)

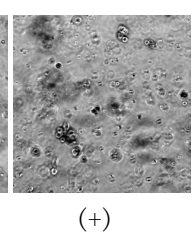

$(+)$

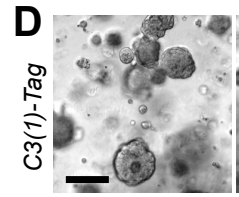

$\begin{array}{ll}\text { Cisplatin } & (-) \\ T_{c d B}{ }^{F B D} & (-)\end{array}$

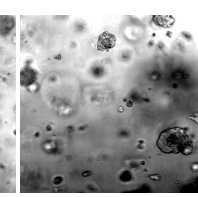

$(+)$

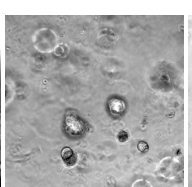

$(-)$

(+)

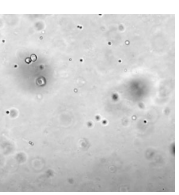

$(+)$

(+)
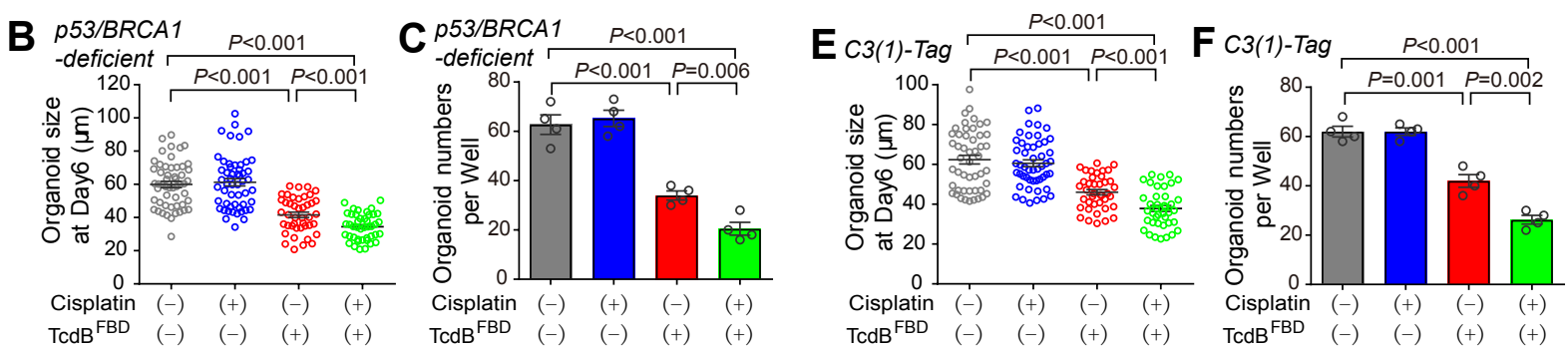


\section{Figures}
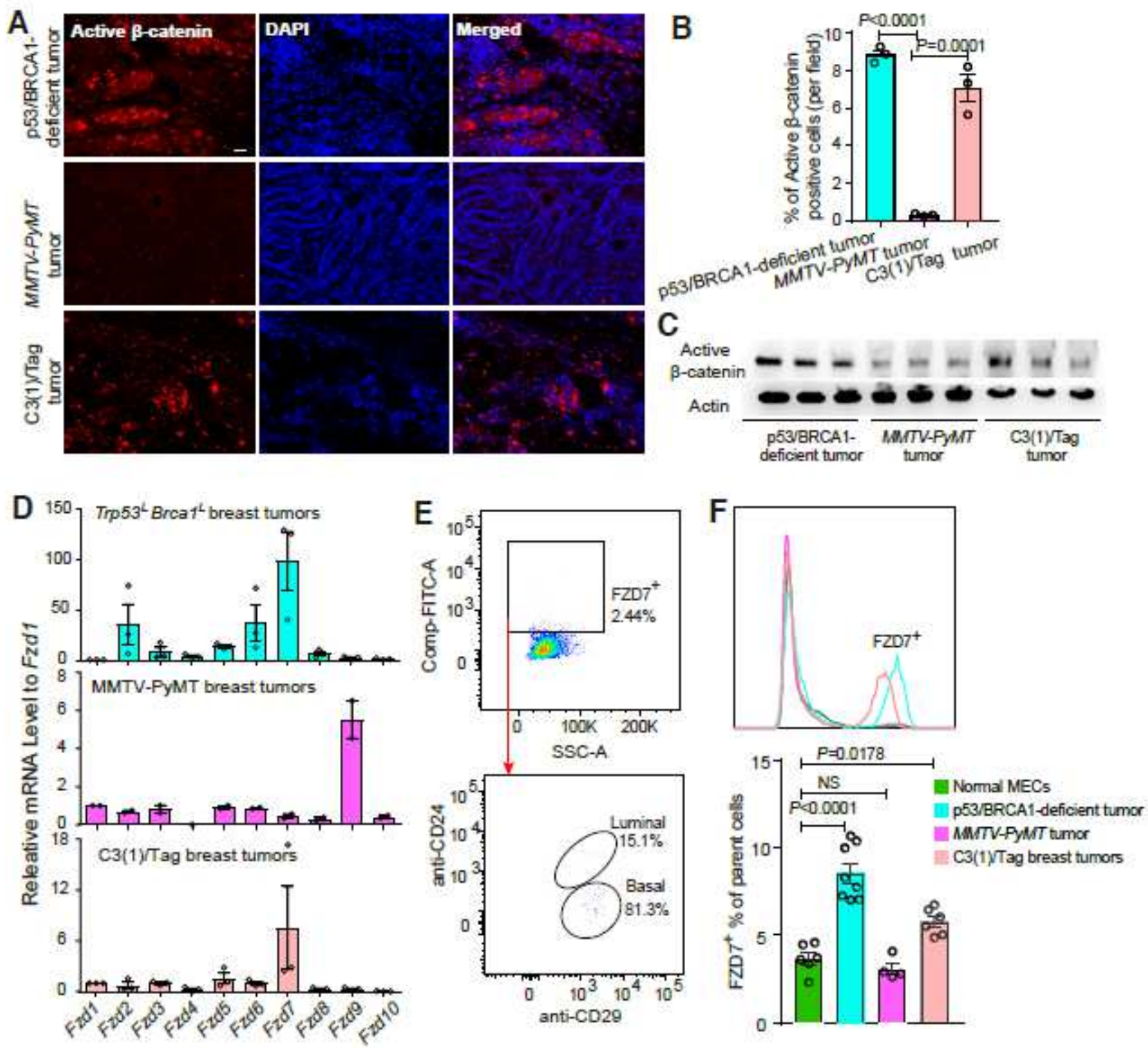

\section{Figure 1}

Wnt/FZD7 signaling is active in basal-like mammary tumors. (A) Representative immunostaining images detecting the levels of active \-catenin (non-phosphorylated form) in tumor tissues from p53/BRCA1deficient, MMTV-PyMT and C3(1)-Tag breast cancer mouse models. DAPI staining marks the cell nucleus.

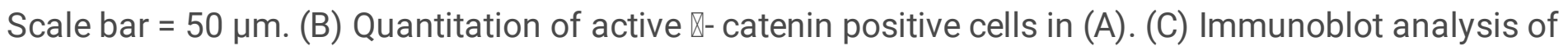

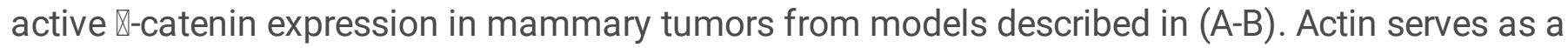
loading control. (D) Quantitative real-time (qRT)-PCR analysis of expression of Fzd family genes in p53/BRCA1- deficient $(n=3)$, C3(1)-Tag $(n=3)$ and MMTV-PyMT $(n=2)$ tumors; error bars indicate mean \pm SEM. (E) Upper panel: FACS analysis using a FZD7-specific antibody identified $~ 2.44 \%$ cells as FZD7+ in normal mammary epithelial cells (MECs). Lower panel: FZD7+ cells were isolated and subjected to further FACS analysis using antibodies against CD24 and CD29 to differentiate basal versus luminal EMCs, 
revealing that $\sim 81.3 \%$ of FZD7+ cells are basal EMCs. (F) The percentages of FZD7+ cells in p53/BRCA1deficient, C3(1)-Tag and MMTV-PyMT tumors, as well as in normal mouse mammary glands, were analyzed by FACS. The FZD7+ peaks are marked and compared in the upper panel and quantified in the lower panel (The P values for p53/BRCA1-deficient, C3(1)-Tag and MMTV-PyMT models were $<0.0001$, $0.8556,0.0178$ respectively compared to normal mouse mammary glands). The representative FACS plots are shown in Supplementary Fig. 3.
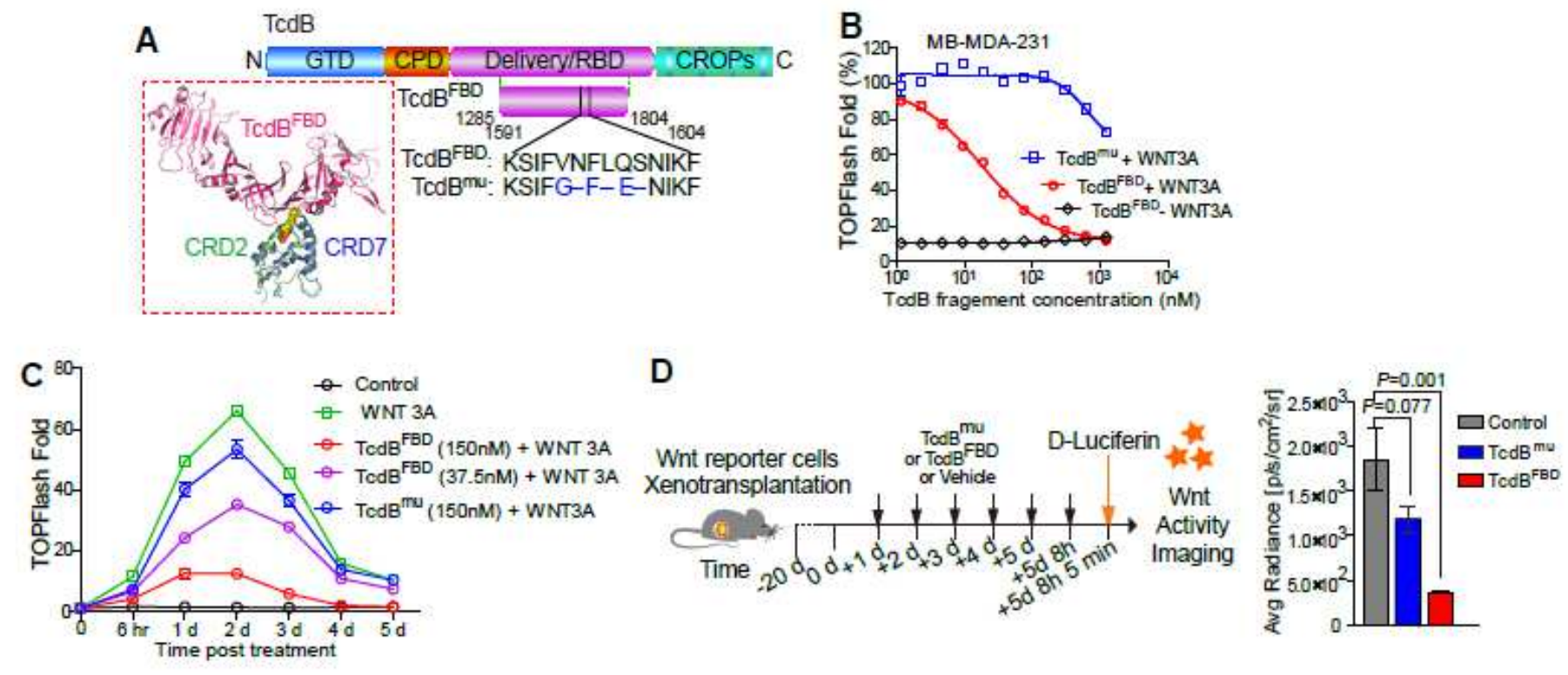

\section{Figure 2}

TcdBFBD inhibits FZD1/2/7-mediated Wnt signaling. (A) Schematic diagrams showing the domain structures of $T c d B$, and the two short fragments derived from TcdB (TcdBFBD and TcdBmu) used in this study. GTD: glucosyltransferase domain; CPD: cysteine protease domain; Delivery/RBD: membrane translocation and receptor-binding domain; CROPs: combined repetitive oligopeptides domain. The structural model of TcdBFBD-CRD7 complex shown is modeled based on the crystal structure of TcdBFBD-CRD2 (PDB code: 6COB) and CRD7 (PDB code:5T44). TcdBFBD, CRD2, and CRD7 are colored pink, green, and blue, respectively. CRD: cysteine-rich domain. (B) TcdBFBD blocked WNT3A-mediated signaling in MDA-MB-231 cells in a dose-dependent manner, whereas TcdBmu showed no inhibition at nanomolar concentrations. Wnt signaling activity was analyzed using the TOPFLASH/TK-Renilla (TK/RL) dual luciferase reporter assay (error bars indicate mean \pm SEM, three independent experiments). (C) Wnt signaling activity in MDA-MB-231 cells was monitored using TK/RL assays over 5 days after induction by WNT3A conditioned medium with the indicated concentrations of TcdBFBD or TcdBmu. Error bars indicate mean \pm s.e.m, three independent experiments. (D) Nude mice were subcutaneously transplanted with TK/RL-transduced MDA-MB-231 cells and then treated at the indicated time point with TcdBFBD or TcdBmu (20 mg/kg of body weight) by intraperitoneal (i.p.) injection. D-Luciferin was injected 5 min before tumor tissues were isolated and the luciferase activity in tumor tissues was then measured ex vivo and quantified (error bars indicate mean $\pm S E M, n=4-5$ tumors). 

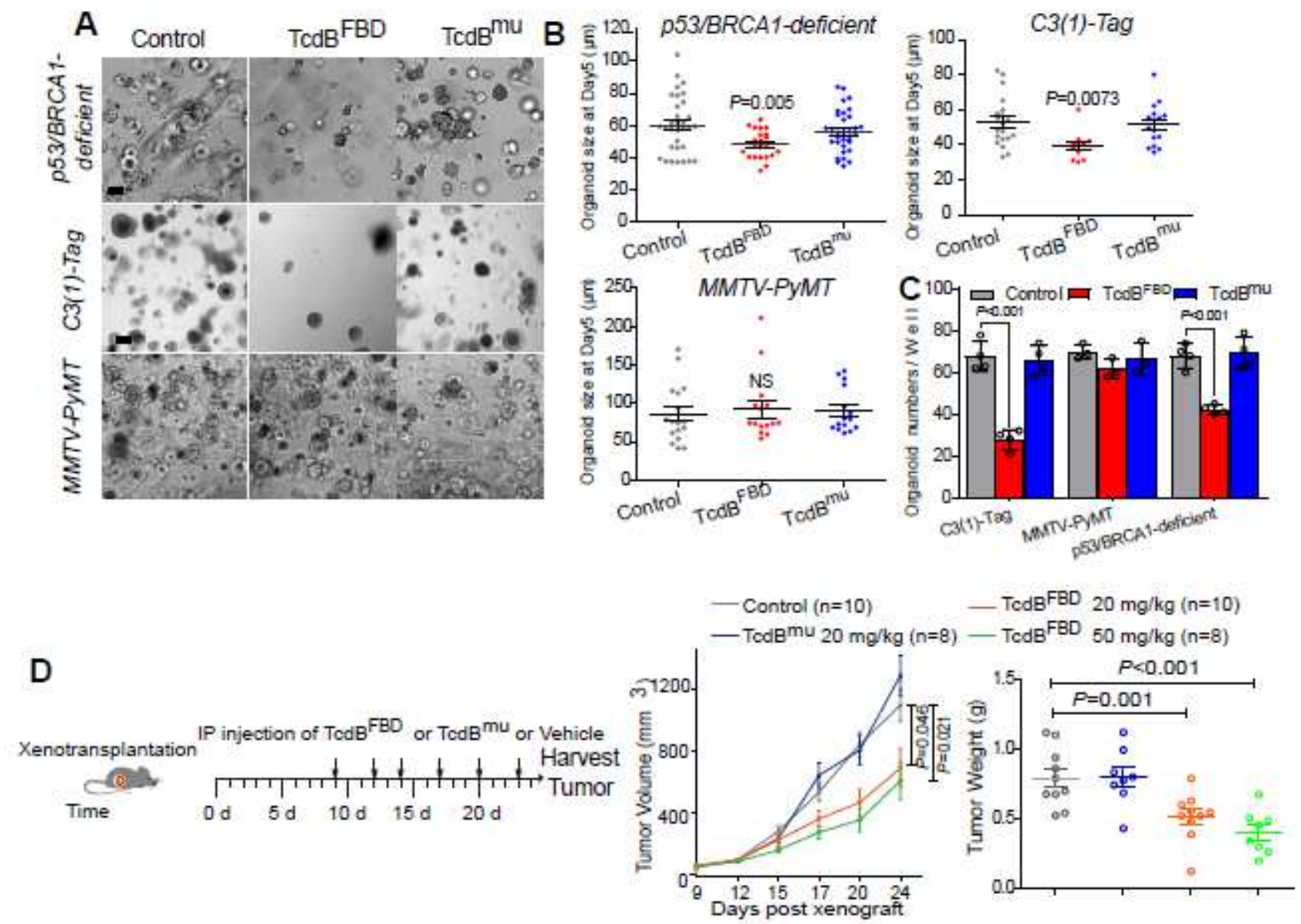

p53/BRCA1-deficient

\section{Figure 3}

TcdBFBD inhibits growth of BL mammary tumors. (A) 2000 cells digested from the indicated primary tumors were seeded in $20 \mu \mathrm{l}$ Matrigel in a 48-well-plate. TcdBFBD or TcdBmu (150 nM) was added to the culture medium once per day. PBS was used as a vehicle control. Representative images of tumor organoids at day 5 in culture are shown. Scale bar $=100 \mu \mathrm{m}$. (B) Quantitation of organoids sizes at day 5 in culture for the indicated groups in (A). (C) Quantitation of organoid numbers at day 5 in culture. (D) Mice were subcutaneously transplanted with p53/BRCA1-deficient mammary tumor organoid cells $(10,000$ cells per mice) and treated for the indicated period when tumor volumes reached $50 \mathrm{~mm} 3$ (left panel). The averaged tumor volumes over time were measured and plotted (middle panel). Tumor tissues were harvested at day 24 and weighted (right panel). Error bars represent SEM of 8-10 independently injected mice. 

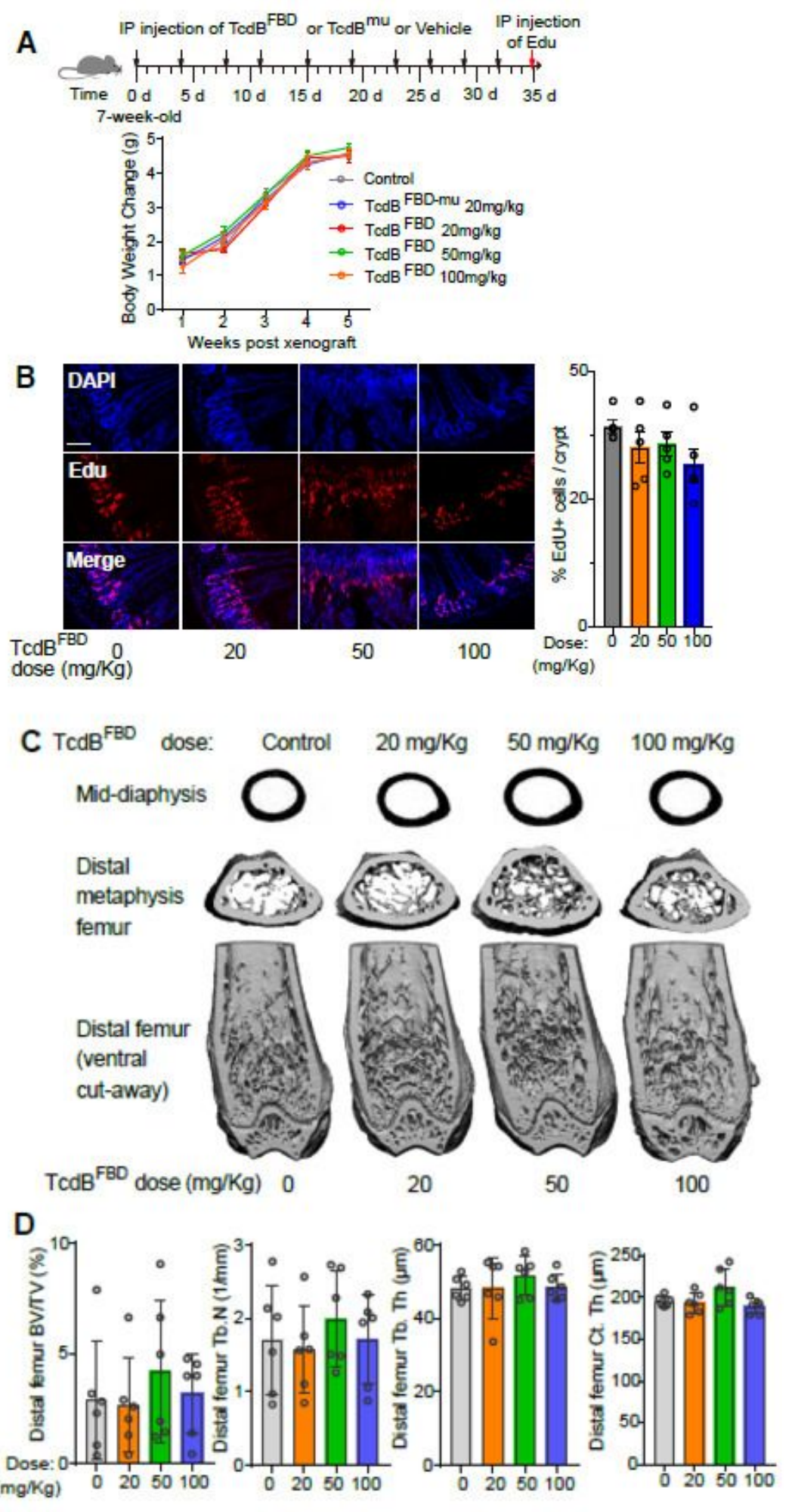

\section{Figure 4}

TcdBFBD treatment in vivo does not affect the intestine and bones. (A) Six weeks old female nude mice (Hsd: Athymic Nude-Foxn1 nu) were injected (i.p.) with the TcdBFBD (20, 50, or $100 \mathrm{mg} / \mathrm{kg}$ ) or TcdBmu $(20 \mathrm{mg} / \mathrm{kg})$ twice a week for five weeks. Their body weight gains were monitored and plotted. Error bars indicate mean \pm SEM, $n=8-10$ mice. (B) Mice were treated with TcdBFBD as described in panel A. EdU was injected (i.p., $100 \mathrm{mg} / \mathrm{kg}$ ) $12 \mathrm{~h}$ before euthanization. Intestine tissues were harvested, fixed, and 
analyzed. The representative images were shown in the left panel and quantification of the percentage of EdU-positive cells per crypt was plotted in the right panel. Scale bar $=200 \mu \mathrm{m}$. $P=0.28$. (C) Mice were treated with TcdBFBD as described in panel $A$ and their right femur bones were extracted, fixed, and subjected to micro-computed tomography $(\mu \mathrm{CT})$ analysis. Representative $\mu \mathrm{CT}$ reconstructions of the midshaft femur cortical bone (upper row), distal femur metaphyseal bone (middle row), and entire distal femur with the ventral half of the femur digitally removed to reveal the cancellous compartment (lower row) are shown. $N=6$ /dose group. (D) Quantification of the $\mu \mathrm{CT}$ analysis described in panel $\mathrm{C}$ for trabecular bone volume fraction (BV/TV), trabecular number (Tb.N), trabecular thickness (Tb.Th), and cortical area (Ct.Ar), $P=0.67,0.63 .0 .68,0.67$, respectively.
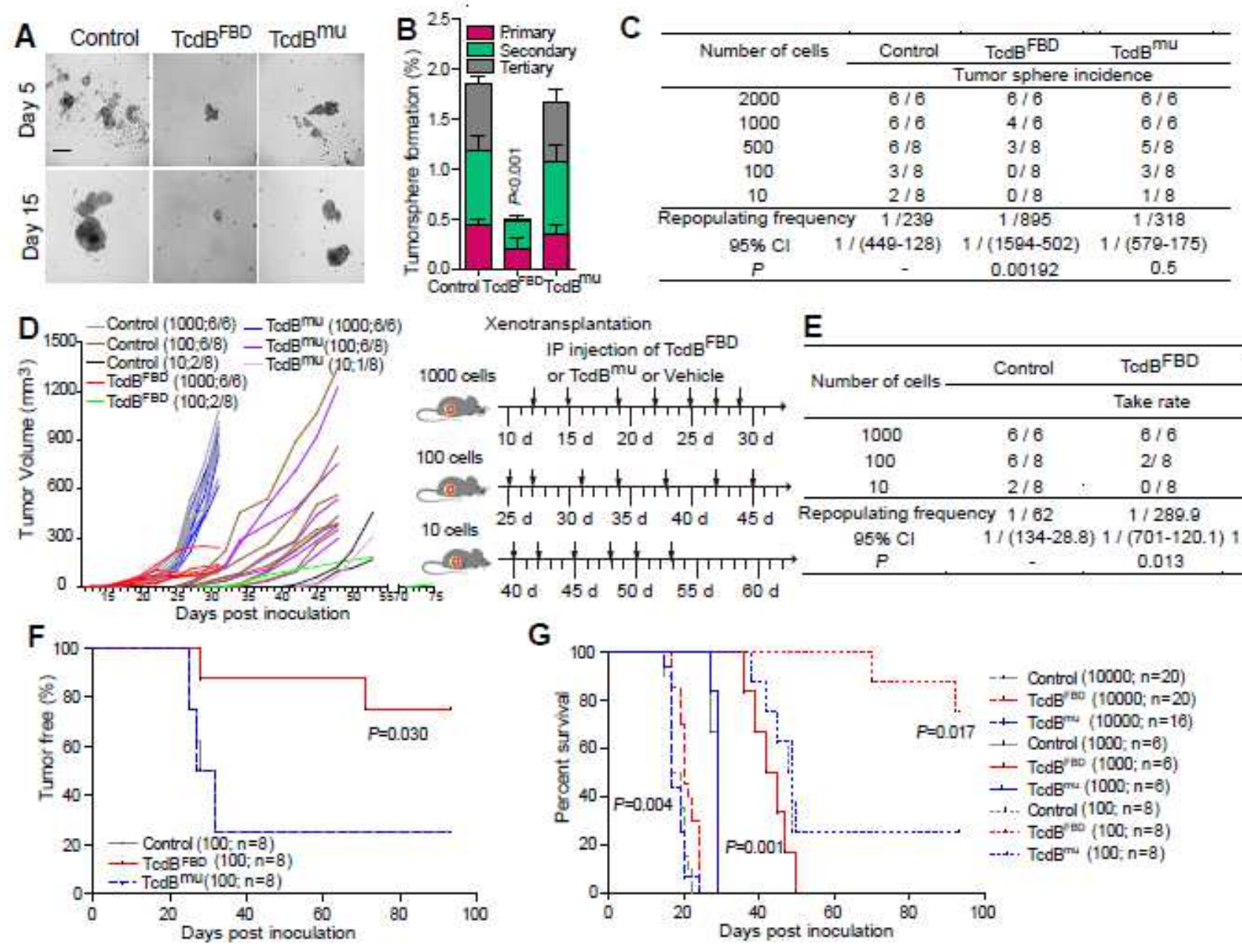

\begin{tabular}{cccc}
\hline & \\
Number of cells & Control & TcdB FBD & TcdB $^{\mathrm{mu}}$ \\
\cline { 2 - 4 } & \multicolumn{3}{c}{ Take rate } \\
\hline 1000 & $6 / 6$ & $6 / 6$ & $6 / 6$ \\
100 & $6 / 8$ & $2 / 8$ & $6 / 8$ \\
10 & $2 / 8$ & $0 / 8$ & $1 / 8$ \\
\hline Repopulating frequency $1 / 62$ & $1 / 289.8$ & $1 / 73.1$ \\
$95 \% \mathrm{Cl}$ & $1 /(134-28.8)$ & $1 /(701-120.1)$ & $1 /(160-33.4$ \\
$\mathrm{P}$ & - & 0.013 & 0.765 \\
\hline
\end{tabular}

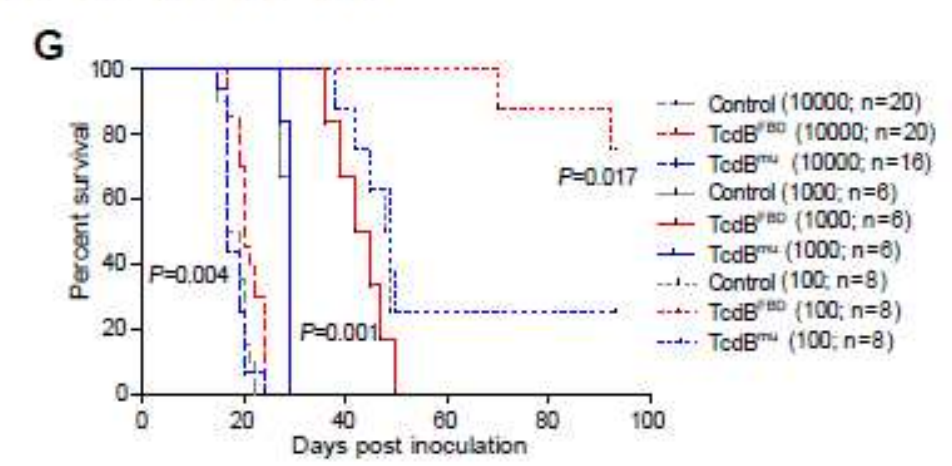

\section{Figure 5}

TcdBFBD inhibits tumorigenic potential of BL mammary tumor cells. (A) Cells dissociated from p53/BRCA1-deficient mammary tumor tissues were resuspended and plated into round-bottom 96-well ultralow attachment plates in the sphere culture medium containing with $150 \mathrm{nM}$ TcdBFBD, TcdBmu, or PBS (control). Representative images of tumorspheres formed at day 5 and day 15 in culture are shown. Scale bar $=200 \mu \mathrm{m}$. (B) The percent of tumorspheres were quantified following three passages of p53/BRCA1-deficient mammary tumor cells (5,000 cells/well for primary culture, and 2,000 cells/well for 
secondary and tertiary culture) with $150 \mathrm{nM}$ TcdBFBD or TcdBmu or PBS in the sphere culture medium. (C) Analysis of the sphere-forming capabilities of p53/BRCA1-deficient mammary tumor cells using the limiting dilution assay. Cells were seeded in the presence of $150 \mathrm{nM}$ TcdBFBD or TcdBmu or PBS vehicle. Sphere formation was counted 10-15 days post-seeding. The frequency of sphere-forming cells (TICs) was calculated using the ELDA website (http://bioinf.wehi.edu.au/software/elda/index.html): Control = 1/239 (lower 449, upper 128); TcdBFBD =1 / 895 (lower 1,594, upper 502), P= 0.00192, compared with control, TcdBmu =1 / 318 (lower 579, upper 175). (D) Tumor organoid cells (10, 100, or 1000 cells) derived from p53/BRCA1-deficient tumors were injected subcutaneously into nude mice. The growth of tumor was evaluated daily for 3-month. Once one tumor grows out in each group (10,100, or 1000 cells), the mice was divided into three groups, received one of the following treatments twice a week: PBS (150 $\mu \mathrm{L} /$ mice), endo-toxin free TcdBFBD (20 mg/ $\mathrm{kg})$, or TcdBmu ( $20 \mathrm{mg} / \mathrm{kg}$ ). Values in brackets indicate the number of organoid cells, the number of tumors obtained versus the total injected mice number. $(E)$ Analysis of the tumorigenesis of p53/BRCA1-deficient mammary tumor organoid cells using the limiting dilution assay as described in (D). Frequency of TICs: Control = 1/62 (lower 134, upper 28.8); TcdBFBD $=1 / 289.9$ (lower 701, upper 120.1), P = 0.0013, compared with control, TcdBmu =1/73.1 (lower 160, upper 33.4). (F) Tumor latency plotted as percentage of tumor-free mice implanted with 100 p53/BRCA1deficient mammary tumor organoid cells following the indicated treatment. (G) Kaplan-Meier survival curves of nude mice bearing xenograft tumors treated as indicated. 
A

53/BRCA1-deficient breast tumor cells Cenotransplantation of to Time $0 d$ d $5 d$ d $10 d$ d $15 d 20 d 25 d$ t IP injection of TodB FBD $(50 \mathrm{mg} / \mathrm{kg})$ or Vehicle * IP injection of Cisplatin ( $5 \mathrm{mg} / \mathrm{kg}$ )

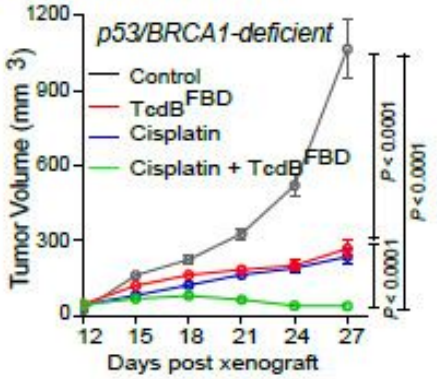

- Control

$\rightarrow$ Cisplatin

- Cisplatin + TodB $F B D$
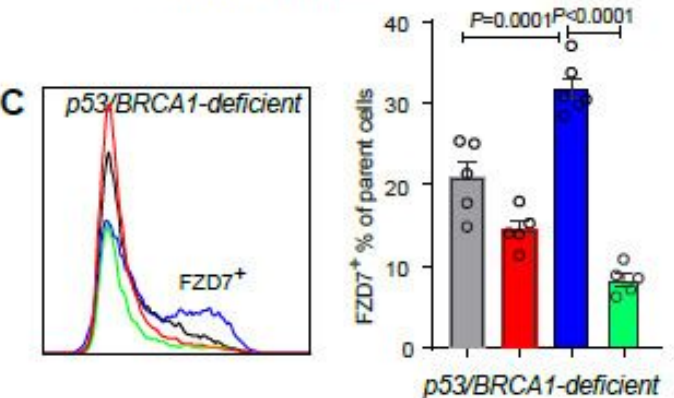

B C3(1)-Tag breast tumor cells

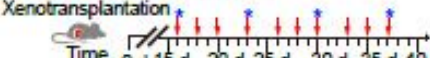

I IP injection of TculB FBD $(50 \mathrm{mg} / \mathrm{kg})$ or Vehicle

$\star$ IP injection of Cisplatin (5 mg/ $\mathrm{kg}$ )
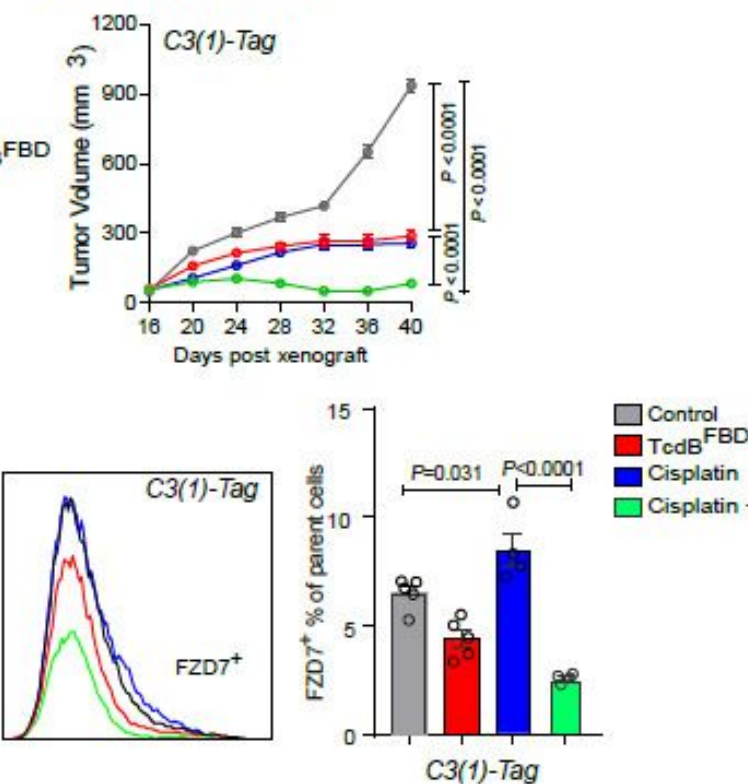

$\square$ Cisplatin

Cisplatin + TcdB $\mathrm{FBD}$
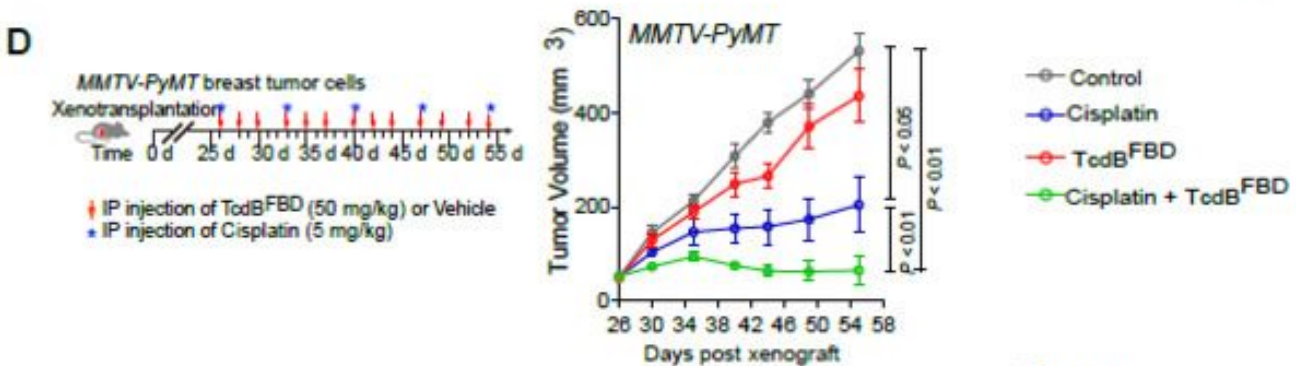

IP injection of TodB $F B D(50 \mathrm{mg} / \mathrm{k})$
$*$ IP injection of Cisplatin ( $5 \mathrm{mg} / \mathrm{kg}$ )

Days post xenograt
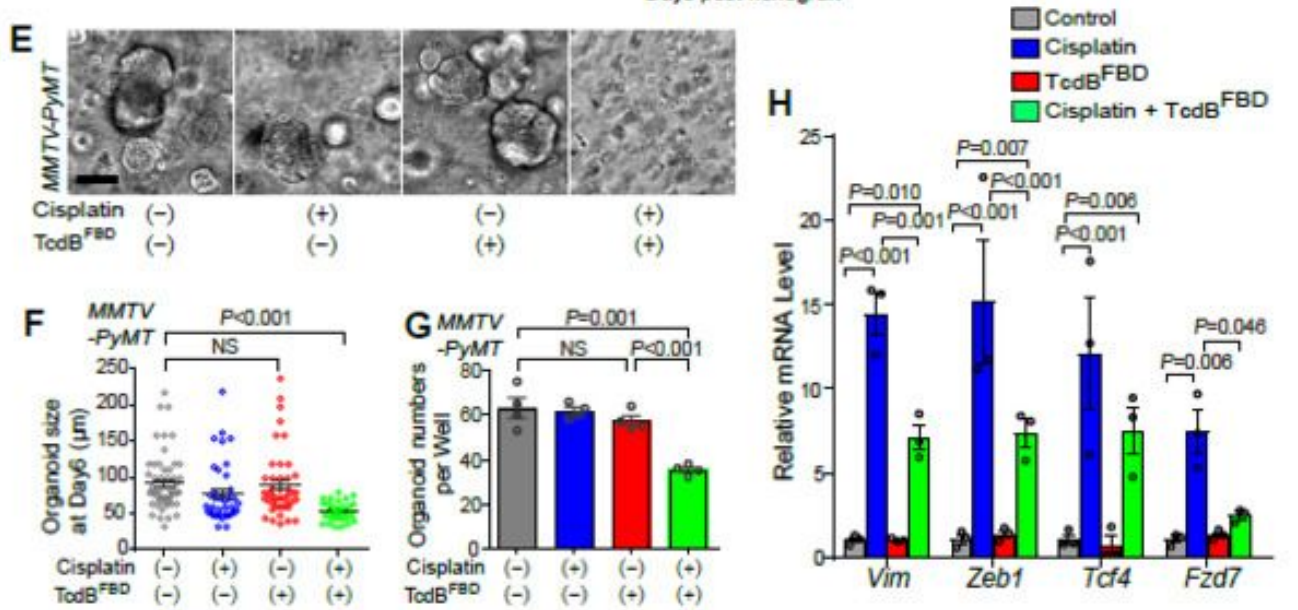

\section{Figure 6}

TcdBFBD inhibits cisplatin-resistant mammary tumor cells. (A-B) Tumor organoid cells from p53/BRAC1deficient tumor model (A) or C3(1)-Tag model (B) were injected into nude mice, and mice were then treated with TcdBFBD alone, cisplatin alone, or a combination of both TcdBFBD and cisplatin as indicated. Tumor volume were recorded and plotted over time. Error bars indicate mean $\pm S E M, n=8$ mice. (C) FACS analysis of FZD7+ cells in the indicated tumors from p53/BRCA1-deficient $(n=5)$ and C3(1)-Tag 
$(n=4)$ models. Error bars indicate mean \pm SEM. (D) Tumor organoid cells from MMTV-PyMT model were injected into nude mice, and mice were then treated with TcdBFBD alone, cisplatin alone, or a combination of both TcdBFBD and cisplatin as indicated. Tumor volume were recorded and plotted over time. Error bars indicate mean \pm SEM, $n=6-8$ mice. (E) Representative images of MMTV-PyMT mammary tumor organoids treated with TcdBFBD alone $(150 \mathrm{nM})$, cisplatin alone $(0.2 \mu \mathrm{M})$, or a combination of cisplatin and TcdBFBD. Scale bar $=100 \mu \mathrm{m}$. (F) Quantitation of organoid sizes for indicated groups described in (E). (G) Quantitation of organoid numbers for indicated groups described in (E). (H) qRT-PCR analysis of EMT-related genes (Vim, Zeb1, Tcf4) and Fzd7 genes in tumor cells from MMTV-PyMT model after treatment with TcdBFBD, cisplatin, or a combination of both $(P<0.01)$.

\section{Supplementary Files}

This is a list of supplementary files associated with this preprint. Click to download.

- FigS1final.jpg

- Figs2.png

- Figs3.png

- Figs4.png

- FigS5.png

- Figs6.png

- Figs7.png

- Figs8.png 